\title{
Indirect Legacy Effects of an Extreme Climatic Event on a Marine Megafaunal Community
}

Robert Nowicki

Florida International University; Mote Marine Laboratory

Michael Heithaus

Florida International University

Jordan Thompson

Deakin University - Victoria, Australia

Derek Burkholder

Nova Southeastern University, <<span class="elink">dburkholder@nova.edu

Kirk Gastrich

Florida International University

See next page for additional authors

Find out more information about Nova Southeastern University and the Halmos College of Natural Sciences and Oceanography.

Follow this and additional works at: https://nsuworks.nova.edu/occ_facarticles

Part of the Marine Biology Commons, and the Oceanography and Atmospheric Sciences and Meteorology Commons

\section{NSUWorks Citation}

Robert Nowicki, Michael Heithaus, Jordan Thompson, Derek Burkholder, Kirk Gastrich, and Aaron Wirsing. 2019. Indirect Legacy Effects of an Extreme Climatic Event on a Marine Megafaunal Community .Ecological Monographs : e01365, 1 -20.

https://nsuworks.nova.edu/occ_facarticles/988. 
Authors

Aaron Wirsing

University of Washington - Seattle Campus

This article is available at NSUWorks: https://nsuworks.nova.edu/occ_facarticles/988 


\title{
Indirect legacy effects of an extreme climatic event on a marine megafaunal community
}

\author{
Robert Nowicki (D) ${ }^{1,2,6}$ Michael Heithaus, ${ }^{2}$ Jordan Thomson, ${ }^{3}$ Derek Burkholder, ${ }^{4}$ Kirk Gastrich, ${ }^{2}$ and \\ AARON Wirsing ${ }^{5}$ \\ ${ }^{1}$ International Center for Coral Reef Research and Restoration, Mote Marine Laboratory, 24244 Overseas Highway, Summerland Key, \\ Florida 33042 USA \\ ${ }^{2}$ Department of Biological Sciences and Marine Education and Research Initiative, Florida International University, Miami, Florida \\ 33199 USA \\ ${ }^{3}$ School of Life and Environmental Sciences, Deakin University, Warrnambool Campus, Warrnambool, Victoria 3280 Australia \\ ${ }^{4}$ Guy Harvey Research Institute, Nova Southeastern University, Ft Lauderdale, Florida 33314 USA \\ ${ }^{5}$ School of Environmental and Forest Sciences, University of Washington, Box 352100, Seattle, Washington 98195 USA
}

Citation: Nowicki R., M. Heithaus, J. Thomson, D. Burkholder, K. Gastrich, and A. Wirsing. 2019. Indirect legacy effects of an extreme climatic event on a marine megafaunal community. Ecological Monographs 00(00):e01365. 10.1002/ecm.1365

Abstract. While extreme climatic events (ECEs) are predicted to become more frequent, reliably predicting their impacts on consumers remains challenging, particularly for large consumers in marine environments. Many studies that do evaluate ECE effects focus primarily on direct effects, though indirect effects can be equally or more important. Here, we investigate the indirect impacts of the 2011 "Ningaloo Niño" marine heatwave ECE on a diverse megafaunal community in Shark Bay, Western Australia. We use an 18-year community-level data set before (1998-2010) and after (2012-2015) the heatwave to assess the effects of seagrass loss on the abundance of seven consumer groups: sharks, sea snakes (multiple species), Indo-pacific bottlenose dolphins (Tursiops aduncus), dugongs (Dugong dugon), green turtles (Chelonia mydas), loggerhead turtles (Caretta caretta), and Pied Cormorants (Phalacrocorax spp.). We then assess whether seagrass loss influences patterns of habitat use by the latter five groups, which are under risk of shark predation. Sharks catch rates were dominated by the generalist tiger shark (Galeocerdo cuvier) and changed little, resulting in constant apex predator density despite heavy seagrass degradation. Abundances of most other consumers declined markedly as food and refuge resources vanished, with the exception of generalist loggerhead turtles. Several consumer groups significantly modified their habitat use patterns in response to the dieoff, but only bottlenose dolphins did so in a manner suggestive of a change in risk-taking behavior. We show that ECEs can have strong indirect effects on megafauna populations and habitat use patterns in the marine environment, even when direct effects are minimal. Our results also show that indirect impacts are not uniform across taxa or trophic levels and suggest that generalist marine consumers are less susceptible to indirect effects of ECEs than specialists. Such non-uniform changes in populations and habitat use patterns have implications for community dynamics, such as the relative strength of direct predation and predation risk. Attempts to predict ecological impacts of ECEs should recognize that direct and indirect effects often operate through different pathways and that taxa can be strongly impacted by one even if resilient to the other.

Key words: climate change; disturbance ecology; extreme climatic event; marine heat wave; phase shifts; predator-prey interactions; resilience; risk effects.

\section{INTRODUCTION}

Most studies of the ecological effects of climate change have focused on how organisms and ecosystems will respond to changes in average climatic conditions as opposed to periodic extreme events (Jentsch et al. 2007, Smith 2011a, Butt et al. 2016). However, extreme

Manuscript received 29 June 2018; revised 3 February 2019; accepted 12 February 2019. Corresponding Editor: A. Randall Hughes.

${ }^{6}$ E-mail: rnowicki@mote.org climatic events (hereafter ECEs), including heat waves, cold snaps, storms, droughts, and floods, can rapidly alter ecosystems and significantly influence patterns of biodiversity (Jentsch et al. 2007, Butt et al. 2016). Climate change is predicted to continue to alter properties of extreme events including their frequency, duration, and intensity (Wu et al. 2012, Cai et al. 2014, 2015, Pachauri et al. 2014, Oliver et al. 2018). Therefore, understanding the impacts of these extremes on communities is key to predicting ecosystem trajectories in coming decades. 
Extreme climate events are defined as abrupt disturbances that exert strong effects over a brief duration relative to the lifespan(s) of the organism(s) under investigation (Jentsch et al. 2007). Climate impacts to ecosystems need not be driven by direct physical forcing to be significant, however (Butt et al. 2016). Indeed, indirect biological impacts of gradual change often supercede direct abiotic effects, at least in freshwater and terrestrial systems (Ockendon et al. 2014). Direct and indirect effects have also been documented for ECEs. Direct physical forcing from ECEs can include mortality, sublethal reductions in fitness, reduced resilience, and changes in behavior (e.g., Breshears et al. 2005, Matich \& Heithaus 2012, Wernberg et al. 2013, Fraser et al. 2014, Thomson et al. 2014). Much like gradual climatic change, ECEs can also impact species indirectly by abruptly altering patterns of resource availability or modifying species interactions (e.g., Preen and Marsh 1995, Cahill et al. 2013, Ockendon et al. 2014, Bennett et al. 2015). Determining the strength, nature, and relative importance of direct abiotic and indirect biotic (i.e., legacy) effects of ECEs is critical for accurately understanding and predicting their effects on consumers. Although legacy effects of climate extremes have been explored in marine environments (e.g., Bennett et al. 2015), they have less commonly been examined over broad taxonomic and spatial scales (Langtimm and Beck 2003, Cahill et al. 2013, Chapman et al. 2014, Butt et al. 2016).

Species interactions are not only altered by climate change, but alter ecosystem responses to it as well (Zarnetske et al. 2012, Cahill et al. 2013, Taylor et al. 2015, Sanders-DeMott et al. 2018). Not all species interactions are equally influential, however (e.g., Paine 1980, 1992, Power et al. 1996). For example, apex predators may be particularly important biotic multipliers of climate change (sensu Zarnetske et al. 2012), in part because of the scale and scope of their interactions with other species and ability to generate widespread nonconsumptive (i.e., "risk") effects in addition to inflicting mortality via direct predation (Jeffries and Lawton 1984, Schmitz et al. 1997, Lima 1998, Dill et al. 2003, Werner and Peacor 2003, Heithaus et al. 2008). Predation risk can greatly alter the behavior of entire prey populations simultaneously and quickly (Lima and Dill 1990, Sinclair and Pech 1996, Creel and Christianson 2008, Creel et al. 2011, Heithaus et al. 2012), sometimes generating behaviorally mediated indirect interactions (BMIIs, also known as behaviorally mediated trophic cascades, or BMTCs; Dill et al. 2003) with strong effects on lower trophic levels (e.g., Schmitz et al. 1997, Ripple and Beschta 2004, Burkholder et al. 2013a). Thus, investigations of the effects of extreme events on species that do not account for impacts on species interactions, especially for strongly interacting species, may fail to predict the overall ecological effects of climate extremes and may hamper understanding of how ecosystems respond to ECEs.
Seagrass ecosystems support diverse consumer communities and provide myriad ecosystem functions including primary production, habitat creation, sediment stabilization, and carbon sequestration and storage (e.g., Costanza et al. 1997, Heck et al. 2003, Orth et al. 2006, Fourqurean et al. 2012, Unsworth et al. 2018). Despite their importance as foundations of coastal ecosystems, seagrass habitats are declining rapidly both because of local stressors (e.g., Short and Wyllie-Echeverria 1996, Waycott et al. 2009) and ECEs (e.g., McKenzie et al. 2012, Fraser et al. 2014, Thomson et al. 2014). Seagrass habitats impacted by ECEs therefore represent a valuable opportunity to test predictions about how resource loss affects abundance and distribution of dependent consumers. For example, are generalist species less vulnerable to ECEs than specialists because of increased adaptive capacity? Do bottom-up stressors from ECEs modify the relative strength of risk effects? And, are species more closely associated with foundational species (e.g., for food or shelter) more at risk from ECEs? Such tests may provide critical insights into our ability to predict how species dynamics will change in response to climate change.

The goal of this study was to investigate the indirect impacts (large-scale seagrass die-off) of an ECE (the 2011 "Ningaloo Niño" marine heatwave) on a taxonomically diverse marine megafaunal community in Shark Bay, Western Australia. Specifically, we analyzed a longterm (18-yr), community-level data set to (1) quantify any legacy effects of the heat wave on the abundance of large sharks and air-breathing marine megafauna and (2) to test whether changes in the resource landscape altered predation-risk-sensitive habitat use patterns of tiger shark (Galeocerdo cuvier) prey. We accomplished this by comparing standardized drumline shark fishing and surface-based belt transect survey data before (1997-2010) and after (2012-2015) the heat wave and subsequent seagrass die-off.

\section{Methods}

Shark Bay $\left(25^{\circ} 45^{\prime} \mathrm{S}, 113^{\circ} 44^{\prime} \mathrm{E}\right)$, Western Australia is a shallow $(<15 \mathrm{~m}), 13,000 \mathrm{~km}^{2}$ semi-enclosed subtropical embayment situated approximately $800 \mathrm{~km}$ north of Perth. The bay historically contained over $4,000 \mathrm{~km}^{2}$ of seagrass (Walker et al. 1988), placing it among the largest seagrass ecosystems on earth. Shark Bay's seagrass assemblage has been historically dominated by the temperate seagrass Amphibolis antarctica, which accounted for approximately $85 \%$ of seagrass cover and often formed dense, monospecific stands of 90-100\% cover (Walker et al. 1988, Burkholder et al. 2013b). Indeed, $A$. antarctica is a structurally complex ecosystem engineer (sensu Jones et al. 1994) that creates extensive benthic habitat, stabilizes sediment, and contributes substantial primary and secondary production (Walker 1985, Walker and McComb 1988). Despite its large size, Shark Bay is largely undeveloped with a small human 
population and relatively few local and regional anthropogenic stressors (Department of Environment and Conservation 2008), making it a good model ecosystem to study natural community responses to ECEs.

The study area, immediately north of Monkey Mia, consists of a series of nearshore shallow $(<4 \mathrm{~m})$ seagrass banks separated by deep, sandy channels (6-12 m, Heithaus 2001; Fig. 1). Since 1997, this study area has been used as a model system to understand the influence of risk effects of tiger sharks on associated prey species and ecosystem structure (Heithaus et al. 2012, Burkholder et al. 2013a, Bessey et al. 2016). Tiger sharks' potential air-breathing prey in this system include megagrazers [dugongs (Dugong dugon) and green sea turtles (Chelonia mydas)], piscivorous mesopredators [Indo-Pacific bottlenose dolphins (Tursiops aduncus), Pied Cormorants (Phalacrocorax spp.), sea snakes (subfamily Hydrophiinae)], and benthic invertivores [loggerhead sea turtles (Caretta caretta), Heithaus et al. 2012]. Generally, shark abundance varied temporally with consistently high shark abundances during warm months (September-May), and very low abundances during most, but not all, winters (June-August; Heithaus 2001, Wirsing et al. 2006). Moreover, tiger sharks used shallow habitats, where seagrasses are concentrated, to a greater extent than deep ones (Heithaus et al. 2002, 2006). These shallow seagrass habitats were characterized by relatively higher density and quality of food resources for megagrazers (dugongs, green turtles) and mesopredators (sea snakes, Cormorants, dolphins), but also carried an increased risk of predation by tiger sharks (see Heithaus et al. 2012). Before the seagrass die-off, multiple consumer species were distributed in rough proportion to their food supply as would be expected by ideal free distribution (IFD) theory (Fretwell and Lucas
1969) when predation risk was low, but overused resource-poor but relatively safe deeper habitats during dangerous periods (Heithaus et al. 2007a,b,c, Heithaus et al. 2012). These shifts in habitat use result in a behaviorally mediated trophic cascade that structured the seagrass community by reducing herbivory from megagrazers in shallow, risky habitats (Burkholder et al. 2013a).

As a subtropical seagrass ecosystem, Shark Bay marks the northern boundary for the temperate seagrass species A. antarctica (Walker et al. 1988). In the Austral summer of 2011, strong La Niña conditions increased the poleward flow of tropical water via the Leeuwin current along the Western Australia coast (Pearce and Feng 2013), generating a strong marine heat wave (MHW; sensu Hobday et al. 2016) that increased water temperatures by $2-4^{\circ} \mathrm{C}$ for two months (Wernberg et al. 2013, Hobday et al. 2016). Within the study area, average daytime water temperatures for the month of February were $29.8^{\circ} \mathrm{C}\left(3.5^{\circ} \mathrm{C}\right.$ above average $)$, and average monthly temperatures remained above the usual yearly maximum from January to March (Nowicki et al. 2017). Following the heat wave, $A$. antarctica cover declined by $\sim 90 \%$ in several areas of Shark Bay (Fraser et al. 2014, Thomson et al. 2014), with the magnitude of seagrass die-off increasing at greater depths (J. Thomson, unpublished data). Seagrass loss of this magnitude had not been previously reported in Shark Bay and a die-off of this magnitude appears not to exist in local living memory (R. Nowicki, personal observation). The seagrass loss was also accompanied by a $\sim 40 \%$ decline in benthic fish biomass in shallow habitats and a $27 \%$ decline in deep habitats (Nowicki and Heithaus unpublished data), as well as a $\sim 50 \%$ reduction in water visibility (Nowicki et al. 2017). A. antarctica cover remained very low

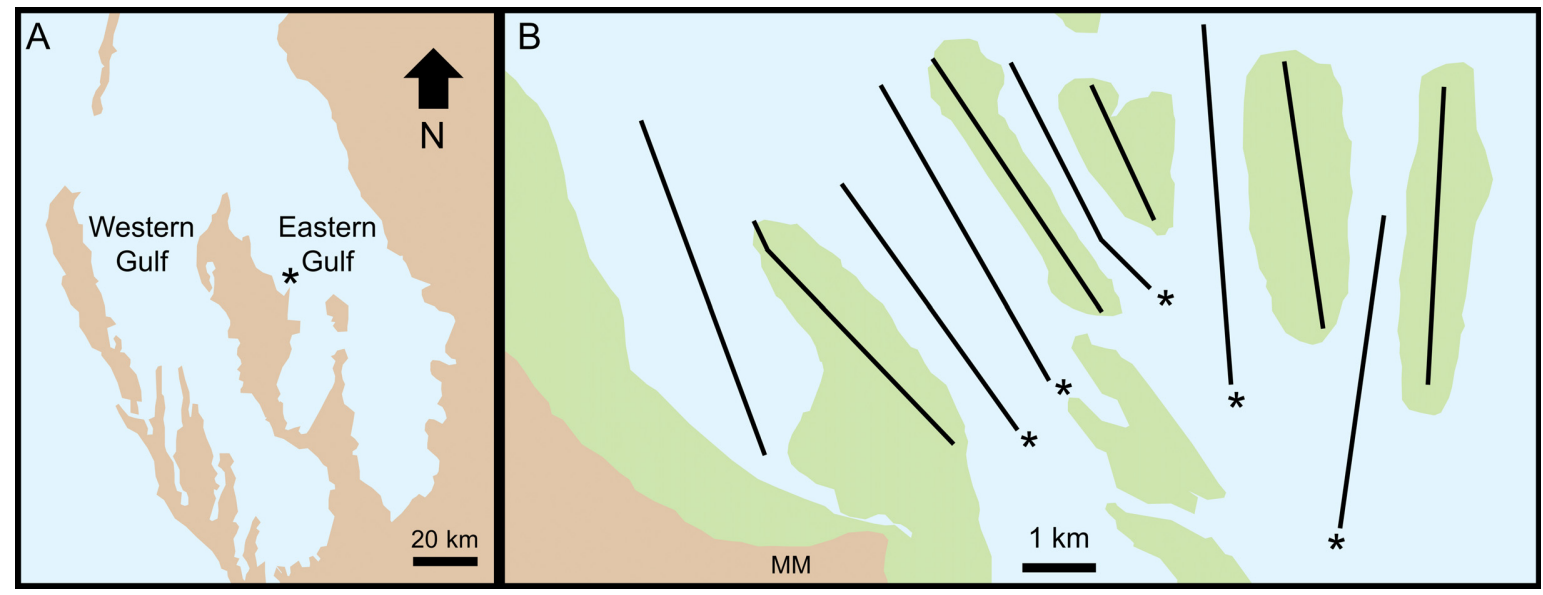

FIG. 1. (A) Shark Bay $\left(25^{\circ} 45^{\prime} \mathrm{S}, 113^{\circ} 44^{\prime} \mathrm{E}\right)$, Western Australia. The study area is located immediately north of Monkey Mia (star in A, and MM in B) in the Eastern Gulf. (B) The study area is typified by a series of shallow $(<4.0 \mathrm{~m})$ seagrass banks (green) separated by deep (6-12 m) sandy channel or plain habitats (blue). Locations of transect surveys are indicated by black lines; brown indicates land. Shark fishing occurred on transects marked with stars, though most sets $(\sim 85 \%)$ were conducted on the easternmost three transects to reduce bait plume proximity to Monkey Mia. Modified from Heithaus (2005). 
following the initial die-off, while the tropical seagrass Halodule uninervis recovered by 2013 and surpassed predisturbance occurrence and cover estimates by 2014 (Nowicki et al. 2017).

\section{Field methods}

Whereas shark fishing and transect surveys occurred in all months, field effort was largely concentrated between February and October to ensure capture of seasonal transitions in shark abundance. Shark abundance was estimated using a standardized top-set drumline method established in 1997 (Heithaus 2001). From 1998 to 2015, we undertook standardized shark sampling via single hook top-set drumlines set in deep channels in the study system (Fig. 1). On each fishing day (approximately $4 \mathrm{~d}$ per field month, mean $=3.90, s=2.03$ ), up to 10 baited drumlines were set at dawn. Drumlines were secured to the bottom with a Danforth anchor (Attwood, Lowell, MI, USA) attached to $20 \mathrm{~m}$ of line. A 25-L floating drum suspended a single baited 13-0 or 14-0 Mustad Shark Hook (O. Mustad \& Son Americas Inc, Miami, FL, USA) 1-2 m below the surface (Heithaus 2001, Wirsing et al. 2006). Some sets were baited with 12-0 sized hooks, but because smaller hooks resulted in lower shark catch rates in this system (Heithaus 2001), these sets were excluded. Drumlines were usually separated by $300 \mathrm{~m}$, though rarely they were set concurrently in two channels with drums $700 \mathrm{~m}$ apart. Previous work has shown these differences in deployment to not influence catch rates (Wirsing et al. 2006) so results from both deployment types were pooled.

Drumlines were baited with $\sim 1.5 \mathrm{~kg}$ of fish. Bait species varied but was dominated by Australian salmon (Arripis trutta, $37.0 \%$ of soak time), pink snapper (Pagrus auratus, 15.7\%), emperor (Lethrinus spp., $14.4 \%$ ), tailor (Pomatomus saltatrix, 13.7\%), and sea mullet (Mugil cephalus, 8.8\%), which collectively made up $\sim 90 \%$ of soak time. Bait species does not significantly influence shark catch rates in this system (Wirsing et al. 2006), so a correction factor for bait species was not applied. Lines were checked every 2-4 h; soak time was calculated as time between bait entry and bait removal. For hooks from which bait was missing or a shark was captured, bait removal was assumed to occur halfway between checks. Hooked sharks were brought along the 4.5-5.5 m research vessel and were allowed to swim freely to minimize stress while the vessel idled forward. Sharks were identified to species, sexed, and measured (total length, TL) before being fitted with a numbered roto-tag and released (see Heithaus [2001] for details).

\section{Transect surveys}

Densities of air breathing megafauna (e.g., dolphins, dugongs, green and loggerhead sea turtles, Cormorants, and sea snakes) were assessed via visual belt transects. Eleven transects, ranging in length from 2.9 to $4.5 \mathrm{~km}$, were established in the study area in 1997, with five over shallow $(<4.0 \mathrm{~m})$ seagrass banks and six over deep (6$12 \mathrm{~m}$ ) channel and sandflat habitats (Heithaus 2001, Fig. 1). Each transect was run between sunrise and sunset approximately four times per month at $6-9 \mathrm{~km} / \mathrm{h}$ using a 4.5-5.5 $\mathrm{m}$ vessel with an outboard motor and approximately three observers $($ mean $=3.24, \mathrm{SD}=1.05$ ) from 1998 to 2014 (excluding 2000, 2001, and 2005). Because of interspecific differences in size and surface behavior, transect radii varied between species (Table 1). Only individuals at the surface that had not been passed by the boat were counted. At each sighting we recorded depth and bottom cover under the boat, as well as distance and heading to the animal.

Slow vessel speeds, relatively short dive times, and direct comparisons within as opposed to among habitat types and seasons in this study minimized the need for detectability correction factors for most species (Wirsing et al. 2007a, Heithaus et al. 2012). To minimize recounting individuals, transects were not run more than once per day, and were run in haphazard order and direction. Cormorants that fled were noted to minimize recounting. Transects were only run in Beaufort sea state conditions of 3 or lower (when wavelets begin to crest) to minimize sampling bias from reduced visibility $(\sim 97 \%$ were $\leq 2$ ). To minimize the influence of large animal groups that were very rarely encountered $(<0.1 \%$ of sighting events), we excluded encounters in which group size exceeded 30 individuals of a species from analysis ( $n=12$ occurrences, all for Cormorants). Furthermore, dolphins were not consistently sampled from 2002 to 2007 , so transects run in these years were removed prior to analysis of dolphin data.

Although the dive profiles of marine turtles can result in significant availability bias for these species (Thomson et al. 2012a, 2013), we did not apply correction factors for several reasons. First, turtle dive profiles and proportional surface use are temperature and depth dependent (Thomson et al. 2012a). Transect surveys were controlled for location and season through time, and temperature regimes were similar between the two time periods (2011 excluded, Nowicki et al. 2017). It is therefore unlikely that availability bias would have

TABLE 1. Transect radii for each species recorded on surface transects.

\begin{tabular}{llc}
\hline \hline Common name & \multicolumn{1}{c}{ Scientific name } & $\begin{array}{c}\text { Transect } \\
\text { radius (m) }\end{array}$ \\
\hline $\begin{array}{l}\text { Indo-Pacific bottlenose } \\
\text { dolphin }\end{array}$ & Tursiops cf. aduncus & 200 \\
Dugong & Dugong dugon & 100 \\
Green turtle & Chelonia mydas & 30 \\
Loggerhead turtle & Caretta caretta & 30 \\
Pied Cormorant & Phalacrocorax varius & 30 \\
Bar-bellied sea snake & Hydrophis elegans & 5 \\
Olive-headed sea snake & Disteria major & 5 \\
Shark Bay sea snake & Aipysurus pooleorum & 5 \\
\hline
\end{tabular}


significantly changed with time within season or habitat type. Furthermore, the vast majority of transects where turtles were sighted consisted of only one or two sightings, representing sometimes less than $10 \%$ of the animals that were likely submerged (Thomson et al. 2012a, 2013). Applying large correction factors when only a single animal is sighted (i.e., without aggregating data to reduce zero inflation) exacerbates overdispersion because no correction factor is applied to transects where no turtle surfaces (but may still be present). We therefore report and analyze uncorrected turtle densities here; actual turtle densities are substantially higher within this system (Thomson et al. 2013). Similarly, because sea turtle surface intervals can be very short, we could not always reliably identify turtles to species. To minimize bias in inferring species-specific turtle response to resource loss, we excluded transects run prior to 1999 (the year identification to species began) and those that included individuals that could not be identified to species. Reliable identification of sea snakes to species was not possible so sea snakes were analyzed as a group.

\section{Data analysis}

Data were analyzed in R Studio version 0.99 .892 (RStudio Team 2015). The $\mathrm{R}$ code used to perform the analyses reported in this paper can be found in Data S1. Data collected in 2011 were excluded from analysis to allow for a clear separation between periods before and after the heat wave. Shark catch per unit effort (CPUE) was expressed as the number of sharks caught per 100 hook soak hours. To reduce zero inflation, all hooks set in a day were pooled to generate a daily CPUE before being summarized (Table 2). Rare days with $<10$ total hook-hours were excluded. Catch rates appear to be a reliable catch per unit effort (CPUE) measure of tiger shark abundance because sighting frequency of freeswimming sharks is directly related to catch rates and sharks tagged with passive acoustic tags $(n=8)$ have only been detected during periods of high catch rates and high prey abundance (e.g., Heithaus 2001, Heithaus et al. 2012; R. Nowicki, personal observation). Furthermore, tiger sharks have been caught even at low winter temperatures, suggesting that changes in catch rates are not because of temperature-induced suspension of feeding (Wirsing et al. 2006; this study).

Shark catch data were analyzed via generalized linear mixed models using the glmer function in the lme4 package (Bates et al. 2015). We calculated CPUE for four subsets of sharks: all sharks, tiger sharks, all "large" sharks ( $>300 \mathrm{~cm}$ TL), and all large tiger sharks (the size at which these animals are thought to become regularly dangerous to dugongs; Wirsing et al. 2007b). In all four models, CPUE was transformed to the 1.5 power to minimize patterns in residuals.

Models had two fixed effects: time period (pre- or post-die-off, 2011 excluded) and a polynomial function of day of year (DOY) meant to capture seasonal trends in shark abundance. Focal zone (FZ) was included as a random effect to account for repeated visits to the same fishing sites, and year was included as a random effect because it is nested within time period (Zuur et al. 2009). Because all hook sets in a day were pooled, rare days in which multiple focal zones were fished simultaneously $(n=7)$ were assigned their own "mixed" FZ designation. The data were positive, continuous, and included a large proportion of zeroes, so a Tweedie distribution (Tweedie 1984) was applied with a power variance structure that varied by model, based on visual inspection of residual data (packages tweedie and statmod; Giner and Smyth 2016, Dunn 2017). Because CPUE is already a property of soak time, a fishing effort offset was not applied.

To assess the impacts of seagrass die-off on the abundance of air-breathing fauna abundances at a systemwide scale, we applied linear mixed-effects models to transect count data using the glmmTMB function in the glmmTMB package (Brooks et al. 2017). In each model, time period was a fixed factor whereas season, habitat, and transect number were included as separate random intercepts (Zuur et al. 2009). The data were positive counts, overdispersed, and often zero inflated. We therefore constructed zero-inflated mixed effects models with three distributions, Poisson, quasi-Poisson (i.e., negative binomial type I), and negative binomial, and used the Akaike information criterion (AIC) to identify the best model for each species following Zuur et al. (2009). Model validation was completed following Zuur et al. (2009) and with the DHARMa package (Hartig 2017) using the simulateResiduals command with 250 iterations.

To determine whether air-breathing fauna altered habitat use patterns following the seagrass die-off, we used zero-inflated mixed models integrating both transect and shark fishing data. Specifically, we assessed whether a three-way interaction between shark catch rate (expressed as monthly CPUE), habitat (deep, shallow), and time period (pre-die-off, post-die-off) influenced the abundance of each species. CPUE was derived from sets in deep channels and was used as a continuous variable estimate of system-wide shark abundance. Focal zone (Fig. 1) was designated as a random effect to account for repeated transect visits. We interpreted a significant three-way interaction to indicate that a group's risk-sensitive habitat use patterns had changed in response to the seagrass die-off. When a three-way interaction was not significant, we used backwards model selection to arrive at a final model in which all terms were significant. Sea snakes were excluded from relative habitat use analysis because post-die-off abundance was very low. Because sharks below $300 \mathrm{~cm}$ TL are not believed to be dangerous to dugongs in this system, we used the CPUE of large (>300 cm TL) sharks in dugong models. 


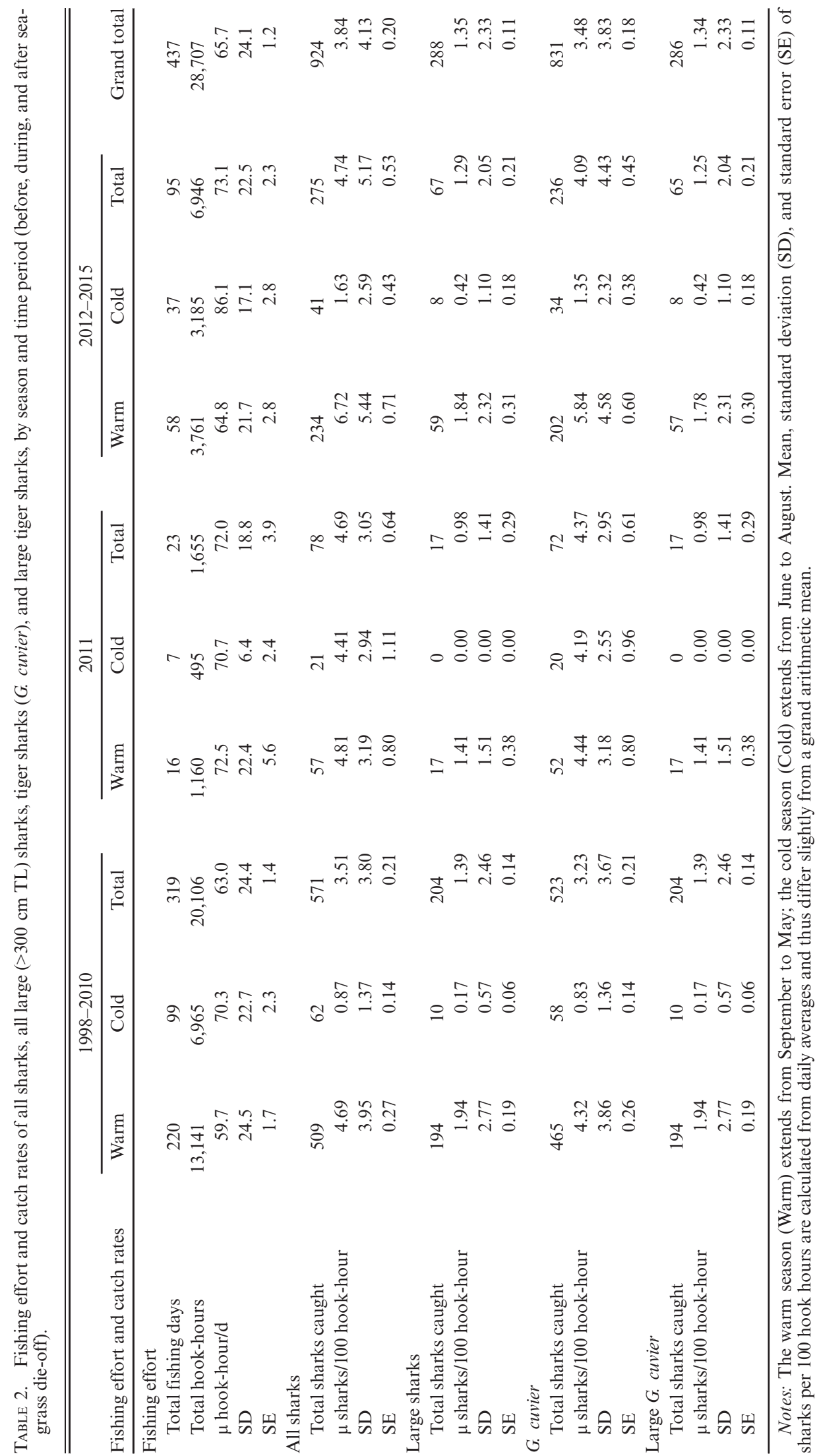




\section{RESULTS}

Our final data set included $437 \mathrm{~d}$ of shark fishing between 1998 and 2015. Exclusion of 2011 data left 27,052 hook hours over 414 fishing days (319 d pre-dieoff, $95 \mathrm{~d}$ post-die-off) for formal analysis. Daily shark fishing effort before the die-off $(\mu=63.0, s=24.4$ hook-hours/d) was lower than after the die-off $(\mu=73.1$ $s=22.5$ hook-hours/d, two-way ANOVA, $F_{1,411}=11.1$, $P<0.001$, Table 2). Daily shark fishing effort was also higher in the cool season $(\mu=74.6 s=22.4$ hook-hours/ d) than the warm season $(\mu=60.8 s=24.0$ hook-hours/ d, two-way ANOVA, $\left.F_{1,411}=32.5, P<0.0001\right)$. There was a marginally significant interaction between the two (two-way ANOVA on interaction term, $F_{1,410}=3.58$, $P=0.059$ ), with pairwise Tukey tests revealing significantly higher soak times in the cold season post-die-off than any other period (Fig. 2).

We caught 924 sharks from 16 species over the course of the study (2011 inclusive, Tables 2 and 3). The shark community was dominated overwhelmingly by tiger sharks (Galeocerdo cuvier, $89.9 \%$ of overall catch) in all time periods, followed by the sandbar shark (Carcharhinus plumbeus). All other shark species were rarely encountered (Table 3). Tiger sharks were even more dominant among large sharks (those $>300 \mathrm{~cm}$ TL), making up $99.3 \%$ of sharks in this size class (Table 3 ). Length measurements of 734 tiger sharks (503 pre-dieoff, 231 post-die-off) revealed that while average tiger shark length declined from $283.3 \mathrm{~cm}$ total length (TL) before the die-off to $264.9 \mathrm{~cm}$ TL after the die-off (Welch two-sample $t$ test, $t_{1,455.6}=-4.20, P<0.0001$ ), the CPUE of the large shark class did not change with time (Tables 2 and 4). Sexing of 664 tiger sharks revealed

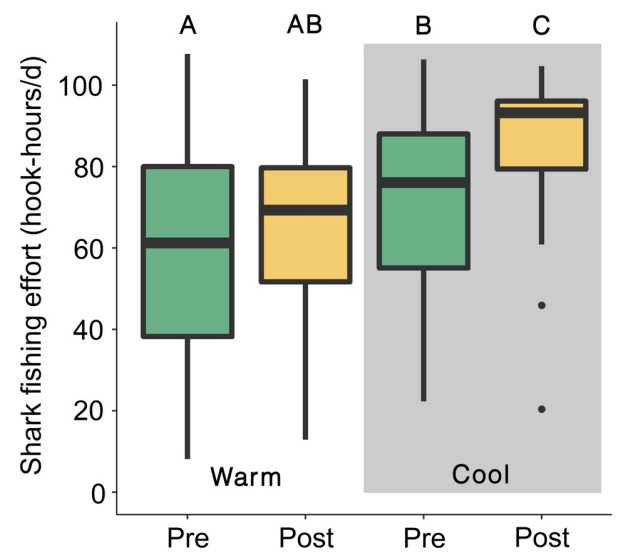

FIG. 2. Shark fishing effort separated into pre-die-off (19982010, green) and post-die-off (2012-2015, gold) periods. Unshaded and shaded areas refer to warm and cool seasons, respectively. Groups that are significantly different from one another (Tukey HSD) are denoted with different letters. Bold lines = medians, box edges $=25$ th and 75 th quartiles, whiskers $=150 \%$ interquartile ranges beyond each quartile, individual points $=$ outliers. that males made up a significantly higher proportion of the population following the die-off: male:female sex ratios changed from $0.29: 1$ to $0.44: 1$ (logistic regression, $\left.Z_{663}=2.41, P=0.016\right)$.

Generalized linear mixed models indicated that overall shark catch rate and seasonal patterns of catch remained similar for all shark groups following seagrass die-off (Table 4, Fig. 3). Because longer soak times yielded lower CPUE both for large sharks (one-way ANOVA, $\left.F_{1,412}=105.3, P<0.0001, R^{2}=0.217\right)$ and sharks in general (one-way ANOVA, $F_{1,412}=107.0$, $\left.P<0.0001, R^{2}=0.206\right)$, and soak times were longer following the seagrass die-off (Fig. 2), the finding of no significant decline in shark catch is robust.

In total we ran 3,375 transect surveys over the study period (2,661 pre-die-off, 714 post-die-off, Table 5), resulting in 12,477 linear kilometers surveyed and 22,371 animals recorded. Of these, 4.8\% (106 of $2,196)$ of pre-decline transects and $6.7 \%$ of postdecline transects (48 of 714) included turtles that could not be identified to species, resulting in 2,756 transects available for turtle analysis (2,090 predecline, 666 post-decline).

Abundances and densities of almost all species dropped significantly following the seagrass die-off (Tables 5 and 6, Fig. 4). Dolphin densities dropped by $39.2 \%$ (ZINB, $\left.z_{1,2,142}=6.02, P<0.0001\right)$, while dugong density was reduced by $67.5 \%\left(Z I N B, z_{1}, 3,360=4.52, P<0.0001\right)$. Similarly, cormorant and green turtle densities declined by $35.3 \%\left(Z I N B, z_{1,3,360}=9.61, P<0.0001\right)$ and $38.6 \%$ $\left(z_{1}, 2,741=2.36, P=0.019\right)$, respectively. Sea snakes suffered the largest losses, declining in density by $76.7 \%$ (ZINB, $\left.z_{1,3,360}=5.46, P<0.0001\right)$. In contrast, loggerhead turtle densities did not significantly differ between time periods (ZIP, $\left.z_{1,2,741}=1.67, P=0.097\right)$.

Habitat use of bottlenose dolphins shifted in a manner consistent with increased risk taking following the seagrass die-off (Table 7). Specifically, bottlenose dolphins' use of risky but profitable shallow seagrass bank habitats was inversely related to shark catch rate prior to the seagrass die off, but this relationship disappeared following the seagrass die-off $(t=-3.32$, $P<0.001$, Table 7, Fig. 5). Conversely, the relationship between shark catch rate and habitat use patterns of cormorants, dugongs, green turtles, and loggerhead turtles did not change significantly following seagrass die-off (Table 7). Instead, loggerhead turtles increased their proportional use of shallow habitats after the die-off independent of shark CPUE, despite a significant influence of CPUE on habitat use generally (Table 7, Fig. 5). Cormorants also increased their relative use of shallow habitats after the die-off, while dugong risk sensitive habitat use patterns remained similarly sensitive to CPUE before and after the dieoff (Table 7, Fig. 5). Green turtle habitat use patterns did not appear to be affected by either shark CPUE or time period. 
TABLE 3. Composition of the large shark community in each time period.

\begin{tabular}{|c|c|c|c|c|c|c|c|c|}
\hline \multirow[b]{2}{*}{ Species } & \multicolumn{2}{|c|}{ 1998-2010 } & \multicolumn{2}{|c|}{2011} & \multicolumn{2}{|c|}{$2012-2015$} & \multicolumn{2}{|c|}{ All years } \\
\hline & $n$ & $\%$ & $n$ & $\%$ & $n$ & $\%$ & $n$ & $\%$ \\
\hline Galeocerdo cuvier & 523 & 91.6 & 72 & 92.3 & 236 & 85.8 & 831 & 89.9 \\
\hline Carcharhinus plumbeus & 31 & 5.4 & 3 & 3.8 & 14 & 5.1 & 48 & 5.2 \\
\hline Negaprion acutidens & 6 & 1.1 & 2 & 2.6 & 1 & 0.4 & 9 & 1.0 \\
\hline Carcharhinus amboinensis & 2 & 0.4 & 0 & 0.0 & 7 & 2.5 & 9 & 1.0 \\
\hline Carcharhinus brevipinna & 0 & 0.0 & 0 & 0.0 & 4 & 1.5 & 4 & 0.4 \\
\hline Carcharhinus cautus & 3 & 0.5 & 0 & 0.0 & 0 & 0.0 & 3 & 0.3 \\
\hline Carcharhinus leucas & 0 & 0.0 & 0 & 0.0 & 2 & 0.7 & 2 & 0.2 \\
\hline Carcharhinus limbatus & 1 & 0.2 & 0 & 0.0 & 1 & 0.4 & 2 & 0.2 \\
\hline Carcharhinus obscurus & 2 & 0.4 & 0 & 0.0 & 0 & 0.0 & 2 & 0.2 \\
\hline Isurus oxyrinchus & 1 & 0.2 & 0 & 0.0 & 1 & 0.4 & 2 & 0.2 \\
\hline Sphyrna mokarran & 0 & 0.0 & 0 & 0.0 & 2 & 0.7 & 2 & 0.2 \\
\hline Carcharhinus brachyurus & 0 & 0.0 & 1 & 1.3 & 0 & 0.0 & 1 & 0.1 \\
\hline Carcharhinus falciformis & 0 & 0.0 & 0 & 0.0 & 1 & 0.4 & 1 & 0.1 \\
\hline Carcharhinus sorrah & 0 & 0.0 & 0 & 0.0 & 1 & 0.4 & 1 & 0.1 \\
\hline Nebrius ferrugineus & 0 & 0.0 & 0 & 0.0 & 1 & 0.4 & 1 & 0.1 \\
\hline Sphyrna lewini & 1 & 0.2 & 0 & 0.0 & 0 & 0.0 & 1 & 0.1 \\
\hline Carcharhinus sp. & 0 & 0.0 & 0 & 0.0 & 3 & 1.1 & 3 & 0.3 \\
\hline Species not recorded & 1 & 0.2 & 0 & 0.0 & 1 & 0.4 & 2 & 0.2 \\
\hline Total & 571 & 100 & 78 & 100 & 275 & 100 & 924 & 100 \\
\hline
\end{tabular}

Note: The percentage of the total shark community is shown.

TABLE 4. Output from generalized linear mixed models derived from shark catch rates.

\begin{tabular}{|c|c|c|c|c|}
\hline Fixed effects & Estimate & SE & $t$ & $P$ \\
\hline \multicolumn{5}{|l|}{ All sharks } \\
\hline DOY (second-order polynomial) & -1.14 & 0.23 & -4.883 & $<0.0001$ \\
\hline Time period (pre vs. post) & 0.02 & 1.27 & 0.02 & 0.988 \\
\hline \multicolumn{5}{|l|}{ All tiger sharks } \\
\hline DOY (second-order polynomial) & -1.04 & 0.25 & -4.22 & $<0.0001$ \\
\hline Time period (pre vs. post) & 0.01 & 1.18 & 0.01 & 0.990 \\
\hline \multicolumn{5}{|l|}{ All large sharks } \\
\hline DOY (second-order polynomial) & -0.88 & 0.18 & -5 & $<0.0001$ \\
\hline Time period (pre vs. post) & -0.03 & 1.46 & -0.2 & 0.984 \\
\hline \multicolumn{5}{|l|}{ All large tiger sharks } \\
\hline DOY (second-order polynomial) & -0.88 & 0.18 & -4.91 & $<0.0001$ \\
\hline Time period (pre vs. post) & -0.03 & 1.47 & -0.02 & 0.983 \\
\hline
\end{tabular}

Note: Intercepts and first-order polynomials are not directly interpretable and thus are excluded for brevity. Significance of the second-order day-of-year (DOY) polynomial coefficient is interpreted as a significant seasonal effect on catch rates. Transect ID (i.e., focal zone) and year were random effects. Variance power differed based on data distribution. Significant model terms are highlighted in boldface text.

\section{Discussion}

Understanding species responses to extreme climatic events, as well as the factors driving such responses, is one of the great emerging challenges in ecology (Jentsch et al. 2007), and has even been codified into some definitions of ECEs (Smith 2011b). However, our understanding of how consumers respond to extreme events is often poor, particularly at the community level and in marine environments (Langtimm and Beck 2003, Cahill et al. 2013). Studies that do focus on ECEs and their impacts often focus on the direct lethal and sublethal effects from physiological stress on individual populations (e.g., Marsh 1989, Matich et al. 2011, Wernberg et al. 2013, Oliver et al. 2017) rather than on the indirect effects of such events, despite the significant effects that legacies (e.g., resource loss) can have on consumers (e.g., Preen and Marsh 1995, Gales et al. 2004, Cahill et al. 2013, Butt et al. 2016). Our results demonstrate that indirect effects from an ECE can have significant and variable effects on abundance and habitat use of consumer communities, even when direct effects are minimal. This finding is notable because it is often difficult to disentangle indirect, legacy effects from direct impacts of physical 

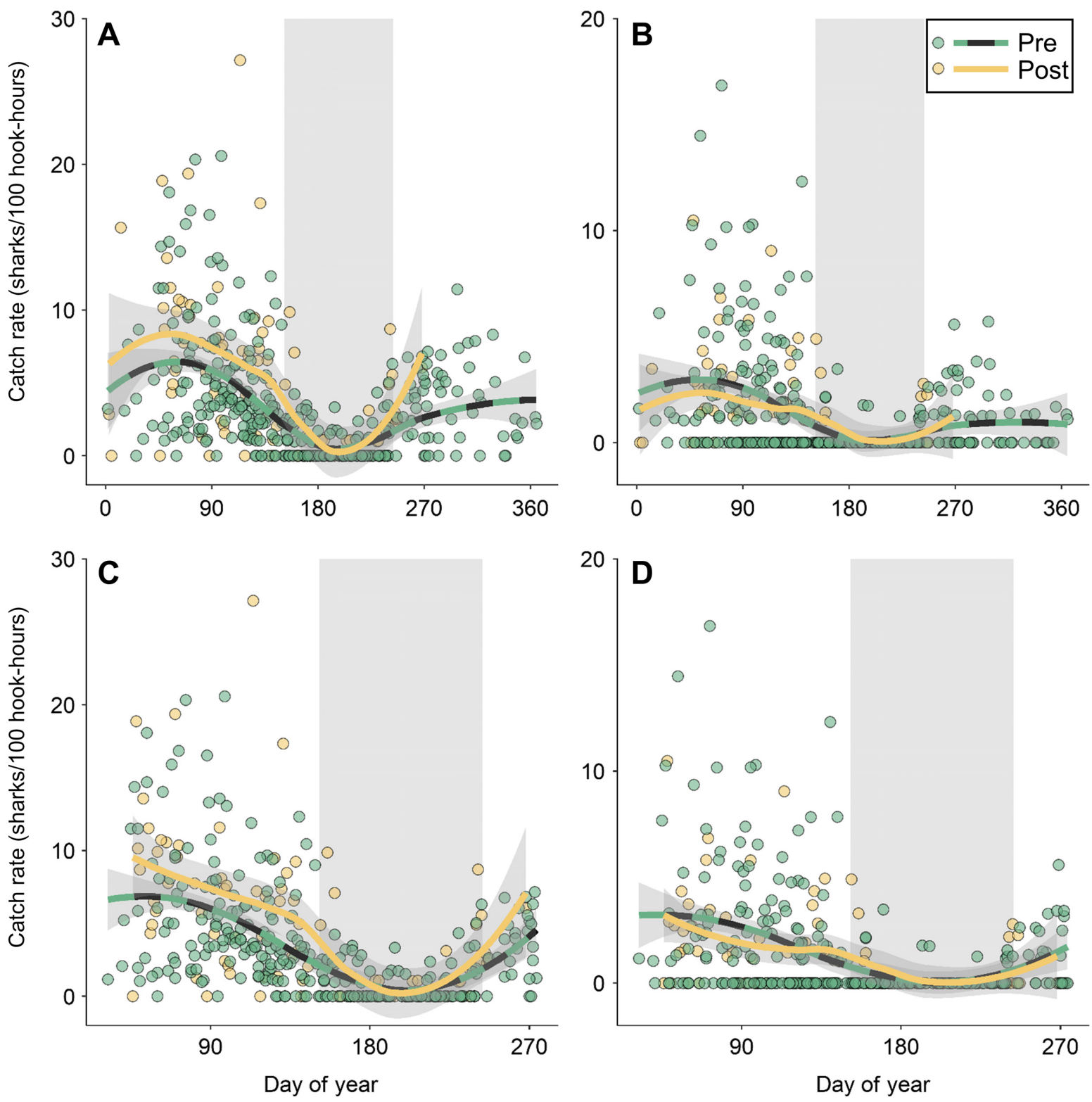

FIG. 3. Catch rates of (A) all sharks and (B) large (>300 cm TL) sharks by day of year and time period. Temporally restricted data sets only including months in which data were collected in both time periods are shown for (C) all sharks and (D) large sharks. LOESS smoothers $($ span $=0.75$ ) with $95 \%$ confidence intervals (shaded buffers) have been applied to better visualize temporal patterns. Note different scales in both $x$ - and $y$-axes. The cold season is represented by the shaded vertical bar.

forcing behind an extreme event (e.g., forest fires, hard freezes). Though we did not explicitly measure the impact of the marine heatwave itself on these consumers, the event did not exceed the thermal tolerance ranges of any of the species studied here, the ranges of all of which (except the Shark Bay Sea Snake, Aipysurus pooleorum) extend far into tropical waters. As such, we are confident that any major changes in habitat use or population size are driven by legacy effects of this extreme event. Overall, we found that populations of generalists were less likely to be impacted by resource loss, while changes to habitat use were more variable and difficult to predict.
Though we were not able to explicitly test the drivers of population declines, observations and knowledge of the biology and ecology of each taxon allows some conclusions to be drawn about likely factors driving each consumer's response, as well as the potential for impacted populations to recover.

\section{Effects of seagrass loss on consumer abundance}

Sharks.-Ecosystem disturbances, including extreme events, can result in direct impacts to shark populations through emigration or mortality (e.g., Heupel et al. 
TABLE 5. Densities of potential tiger shark prey before and after the seagrass die-off.

\begin{tabular}{|c|c|c|c|c|c|c|c|c|c|}
\hline \multirow[b]{2}{*}{ Taxonomic group } & \multicolumn{4}{|c|}{ Pre-die-off (1997-2010†) } & \multicolumn{4}{|c|}{ Post-die-off (2012-2014) } & \multirow[b]{2}{*}{$\begin{array}{c}\Delta \text { relative } \\
\text { density }(\%)\end{array}$} \\
\hline & No. transects & Abundance & Density $\left(\mathrm{km}^{2}\right)$ & $\mathrm{SE}$ & $\begin{array}{c}\text { No. } \\
\text { transects }\end{array}$ & Abundance & $\begin{array}{c}\text { Density } \\
\left(\mathrm{km}^{2}\right)\end{array}$ & SE & \\
\hline Dolphins & 1,443 & 5,152 & 2.30 & 0.09 & 714 & 1,517 & 1.40 & 0.08 & -39.2 \\
\hline Dugongs & 2,661 & 921 & 0.49 & 0.04 & 714 & 77 & 0.16 & 0.03 & -67.5 \\
\hline Cormorants & 2,661 & 10,915 & 20.55 & 0.73 & 714 & 1,886 & 13.29 & 0.75 & -35.3 \\
\hline Loggerhead turtles $\ddagger$ & 2,090 & 371 & 0.77 & 0.05 & 666 & 89 & 0.61 & 0.07 & n.s. \\
\hline Green turtles $\ddagger$ & 2,090 & 355 & 0.83 & 0.06 & 666 & 72 & 0.51 & 0.06 & -38.6 \\
\hline Sea snakes & 2,661 & 420 & 4.69 & 0.31 & 714 & 28 & 1.09 & 0.25 & -76.7 \\
\hline
\end{tabular}

Note: n.s, not significant.

$\dagger$ Turtle data excludes transects run prior to 1999 and for which turtles could not be identified to species. Dolphin data excludes 2002-2007.

\$ Uncorrected densities (see Methods).

TABLE 6. Zero-inflated mixed model results on relative abundance of air-breathing megafauna before and after the marine heatwave.

\begin{tabular}{lclcc}
\hline \hline $\begin{array}{l}\text { Taxonomic } \\
\text { group }\end{array}$ & df & \multicolumn{1}{c}{ Distribution } & $t$ & $\operatorname{Pr}(>|z|)$ \\
\hline Dolphins & $1,2,142$ & negative binomial I & 6.02 & $\mathbf{< 0 . 0 0 0 1}$ \\
Dugongs & $1,3,360$ & negative binomial II & 4.52 & $\mathbf{< 0 . 0 0 0 1}$ \\
Cormorants & $1,3,360$ & negative binomial II & 9.61 & $\mathbf{< 0 . 0 0 0 1}$ \\
Loggerhead & $1,2,741$ & Poisson & 1.67 & 0.097 \\
$\quad$ turtles & & & & \\
Green turtles & $1,2,741$ & negative binomial I & 2.36 & $\mathbf{0 . 0 1 9}$ \\
Sea snakes & $1,3,360$ & negative binomial II & 5.46 & $\mathbf{< 0 . 0 0 0 1}$ \\
\hline
\end{tabular}

Note: Significant changes are highlighted in boldface type.

2003, Matich and Heithaus 2012, Udyawer et al. 2013), though resource loss may also drive shark declines without a triggering extreme event (e.g., Jennings et al. 2008). However, we did not observe an effect of the heat wave or subsequent seagrass die-off on shark abundance. Instead, shark catch rates retained the basic seasonal pattern of this system, with high shark relative abundance in warm months and very low relative abundance in most cool months. Even if demographic impacts of resource loss on predator populations are minimal, however, resource loss can affect other evolutionary and ecological factors impacting predator populations such as predator-prey interactions (Ryall and Fahrig 2006) or phenotypes favored by natural selection (DiBattista et al. 2011). Indeed, tiger sharks captured after the seagrass die-off were on average smaller and more likely to be male than before the seagrass die-off. Importantly, however, the chance of catching large $(>300 \mathrm{~cm}$ TL) tiger sharks, those most able to consume dugongs in this system, remained constant before and after the event.

The insensitivity of tiger sharks to widespread seagrass die-off in this system is predicted by theory; namely, that generalists are expected to be more resilient to habitat loss than specialists (Ryall and Fahrig 2006). Tiger sharks are generalists at the individual level, feeding on fish, other elasmobranchs, sea snakes, gastropods, crustaceans, birds, and marine mammals (e.g., Lowe et al. 1996, Castro 2010, Matich et al. 2011, Ferreira et al. 2017), so local declines in one or even several prey species may not greatly affect tiger shark populations in Shark Bay. Instead, seagrass loss could actually increase short-term shark foraging success, especially on energetically stressed prey that take greater risks to obtain food (Heithaus et al. 2007a), prey that use seagrass for refuge like sea snakes (Kerford et al. 2008, Wirsing and Heithaus 2009), or prey that rely on clear water and visual detection of predators to reduce predation risk (i.e., dugongs, Wirsing et al. 2007a). Tiger sharks can also range widely (e.g., Ferreira et al. 2015), and individuals within Shark Bay rarely reside there for extended periods (Heithaus et al. 2007b). This may drive resilience to resource loss in what is effectively only a part of an individual tiger shark's range.

Sea snakes.-Sea snakes, which are entirely marine, are heavily dependent on seagrass beds to both find prey and seek refuge from predators (e.g., Kerford et al. 2008, Wirsing and Heithaus 2009). This heavy dependence on seagrass, combined with the extremely small home range sizes and limited dispersal potential sea snakes can exhibit (in some cases, one to two orders of magnitude smaller than the study area, e.g., Burns and Heatwole 1998, Lukoschek et al. 2008, Lukoschek and Shine 2012), suggest that the declines we observed were largely driven by mortality, not emigration. It remains unclear, however, the degree to which this putative mortality was driven by starvation vs. predation.

Dugongs.-As obligate seagrass herbivores (Marsh et al. 1982), dugongs are also heavily reliant on seagrass. Though they prefer tropical seagrasses, dugongs in Shark Bay will also crop Amphibolis antarctica shoots when tropical seagrasses are rare or difficult to access (Anderson 1986, Wirsing et al. 2007a). Because the marine heat wave resulted in an initial loss of both 

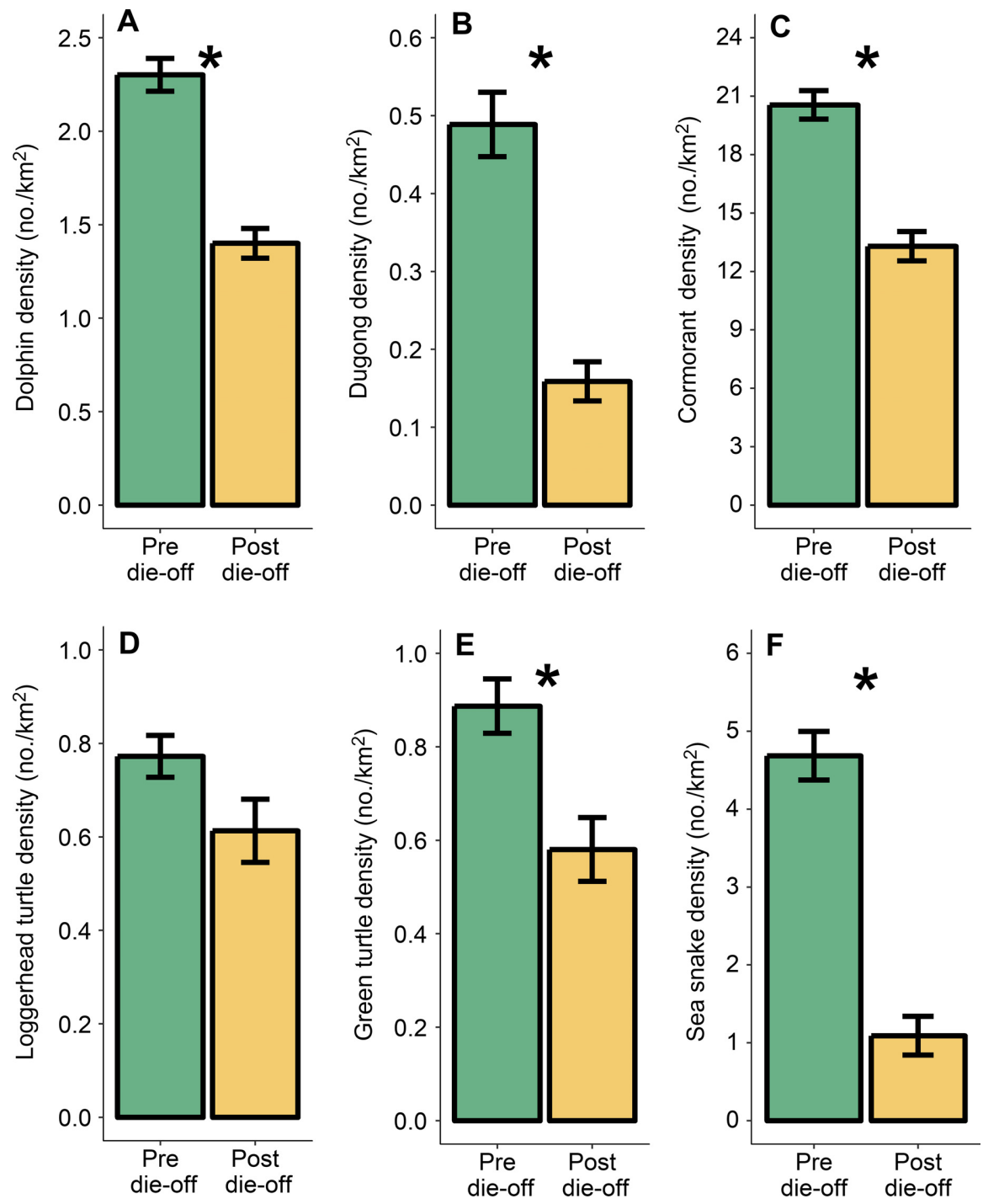

FIG. 4. Changes in landscape-level density of dolphins (A), dugongs (B), cormorants (C), loggerhead turtles (D), green turtles $(\mathrm{E})$, and sea snakes $(\mathrm{F})$ within Shark Bay following the seagrass die-off. Significant differences $(P \leq 0.05)$ are denoted with asterisks. Turtle density comparisons are based on uncorrected densities and are underestimates of true densities in this system. Values are mean \pm SE.

TABLE 7. Zero-inflated generalized mixed model results on habitat use of air-breathing megafauna before and after the seagrass die-off.

\begin{tabular}{llllll}
\hline \hline & & & \multicolumn{2}{c}{ Model interactions } \\
\cline { 3 - 6 } Taxonomic group & Distribution & HAB $\times$ TP $\times$ CPUE & HAB $\times$ TP & HAB $\times$ CPUE & TP $\times$ CPUE \\
\hline Dolphins & negative binomial I & 0.001 & na & na & na \\
Dugongs & negative binomial II & n.s. & n.s. & 0.011 & 0.009 \\
Cormorants & negative binomial II & n.s. & $<0.001$ & n.s. & $<0.001$ \\
Loggerhead turtles & Poisson & n.s. & $<0.001$ & 0.032 & n.s. \\
Green turtles & negative binomial I & n.s. & n.s. & n.s. & n.s. \\
\hline
\end{tabular}

Notes: HAB, habitat (shallow, deep); TP, time period (before or after the heat wave); CPUE, catch per unit effort (number of sharks caught per 100 hook-hours) in deep-channel habitats, used as a continuous estimate of system-wide shark abundance; na, not applicable; n.s, not significant. Two-way interactions were not evaluated when three-way interactions were significant. 

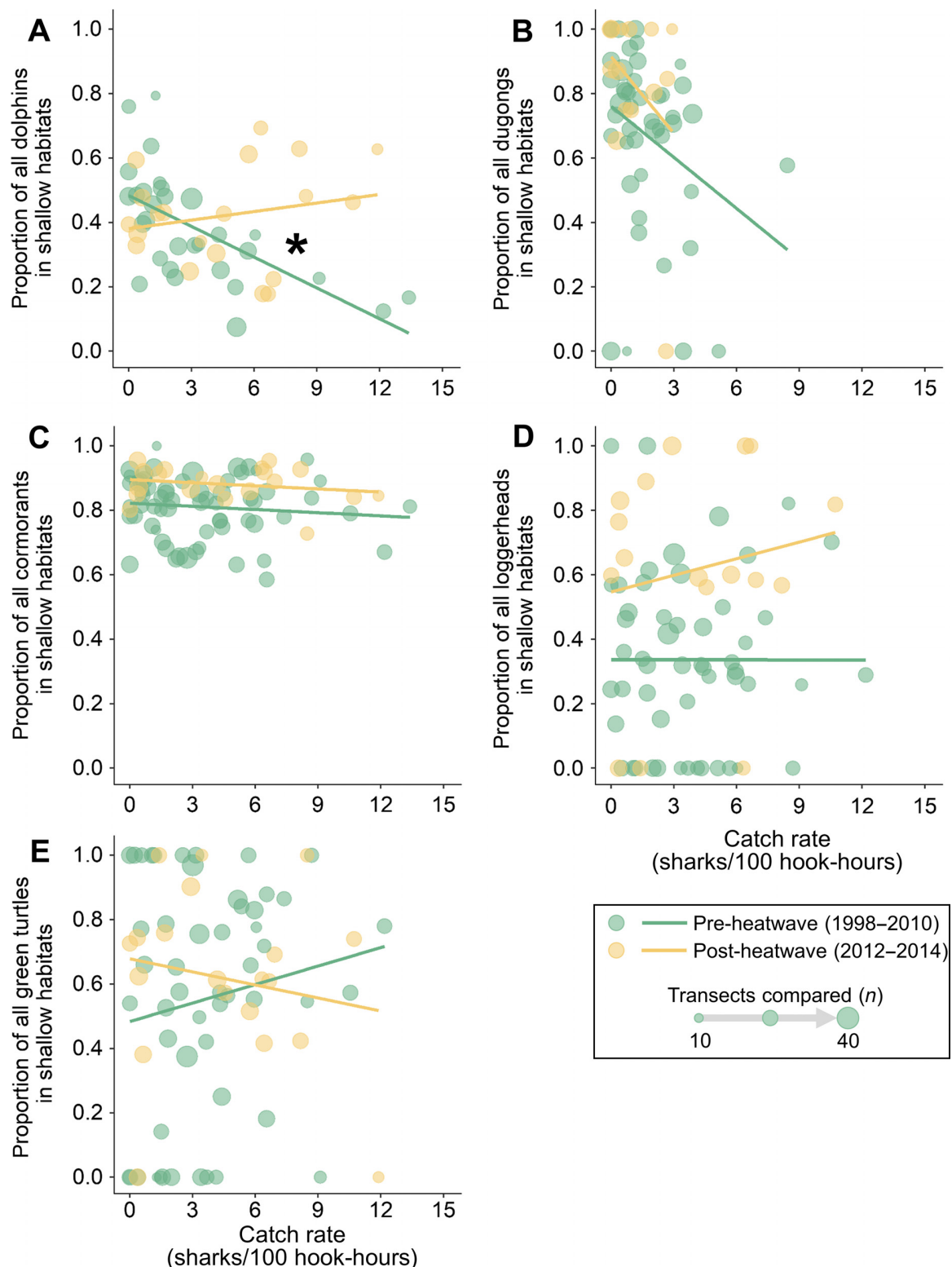

(sharks/100 hook-hours)

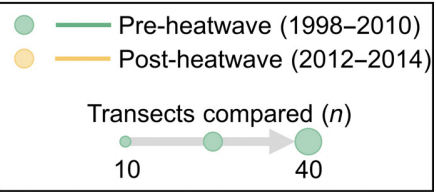

FIG. 5. Changes in proportional habitat use of (A) dolphins, (B) dugongs, (C) Cormorants, (D) loggerhead turtles, and (E) green turtles in relation to shark abundance (as measured by shark catch rate; $x$-axis) and time period (green vs. yellow shading). To facilitate visual interpretation, individual transects were aggregated by month and abundance in each habitat type expressed as a ratio here, with point diameter correlating to the number of transects. Actual statistical analysis occurred on non-aggregated data (see Methods and Table 7). Regressions are weighted by number of transects compared within each month. Catch per unit effort (CPUE) in panel B refers to large sharks only. *significant three way interaction $(P<0.05)$.

A. antarctica and some tropical seagrasses (Thomson et al. 2014, Nowicki et al. 2017), the dugong declines observed here are not surprising.

Dugongs are able to choose habitat based on presence of preferred seagrass food resources, and can maintain a spatial memory of highly productive seagrass beds that they revisit over time (Holley 2006, Sheppard et al. 2006). In Western Australia and elsewhere, dugongs often respond to large-scale seagrass dieback events with long-distance emigration to alternative foraging areas and subsequent reimmigration following recovery of fast-growing tropical seagrasses (e.g., Preen and Marsh 1995, Loneragan et al. 2003, Gales et al. 2004, Holley 2006, Hodgson 2007). When mass dugong mortality does occur, widespread dugong strandings are generally observed (e.g., Marsh 1989, Preen and Marsh 1995, Great Barrier Reef Marine Park Authority 2014). We encountered no dead, dying, stranded, or freshly wounded dugongs during post-heat-wave sampling, and there was no abnormal increase in stranding reports in 
Shark Bay (Department of Parks and Wildlife, personal communication). As such, dugong declines observed here are likely primarily driven by emigration rather than mass mortality. Generally, it remains unclear what mechanisms determine whether dugongs will emigrate or strand in response to seagrass loss: this would be an important area for future research. Because dugongs are capable of strong top-down control on seagrass ecosystems (e.g., Preen 1995), and because tropical seagrass recovery has already begun (Nowicki et al. 2017), a return of dugongs to Shark Bay seems likely, and may have important implications for the recovery trajectory of the system's degraded seagrass community.

Sea turtles. - The differential response of loggerhead and green turtles to seagrass loss can be explained in part by differences in diet and foraging ecology. Loggerhead turtles in Shark Bay are diet generalists that feed largely on benthic invertebrates and other taxa (Thomson et al. 2012b), though they will also scavenge (Seney and Musick 2007). Therefore, seagrass loss might have little short-term impact, or even a temporarily positive one, if search and handling times for benthic crustaceans and bivalves that use seagrass as cover are reduced. In contrast, green turtles in Shark Bay feed on temperate and tropical seagrasses in addition to macroalgae, gelatinous macroplankton, and benthic macroinvertebrates (e.g., sponges, ascidians), with individual turtles specializing on specific diet mixtures (Burkholder et al. 2011, Thomson et al. 2014, 2018). Indeed, following the seagrass die-off, the body condition of captured green turtles declined markedly (Thomson et al. 2014), and extremely emaciated green turtles were repeatedly encountered in the study system between 2012 and 2015 (R. Nowicki, personal observation). This suggests starvation mortality was likely an important driver of the observed decline, though increased risk-taking and reduced escape potential by energetically stressed green turtles in Shark Bay (see Heithaus et al. 2007a) likely also increased mortality to tiger shark predation.

Pied Cormorants.-Cormorants are highly mobile piscivores that use seagrass habitats primarily for foraging. As such, their $\sim 35 \%$ decline in abundance is likely to be linked to the significant reduction in the biomass of seagrass-associated fishes in the system (Heithaus 2004; R. Nowicki et al., unpublished data) on which they primarily feed (Heithaus 2005). In a contemporary study by Cannell et al. (2012) on Little Penguins (Eudyptula minor) on Penguin Island, Western Australia, the 2011 Ningaloo Niño is thought to have driven food reductions and a rise in underweight, dead birds. Cormorant declines in Shark Bay, however, occurred mostly in the cold season (when the breeding season occurs; Dell and Cherriman 2008), suggesting that mortality alone is unlikely to be entirely responsible for observed population reduction.
Bottlenose dolphins.-The mechanism for the $\sim 40 \%$ decline in bottlenose dolphin densities is unclear. Extreme events can cause short-term (i.e., several week) dolphin emigration (e.g., Fury and Harrison 2011) and dolphin abundance is in some places correlated with the ENSO cycle (Sprogis et al. 2018). These factors cannot explain the sustained reduction in dolphin abundance when compared to the previous 12 years of data, however, because the La Niña associated with the 2011 marine heat wave ended in March 2012, when we began post-disturbance data collection (Bureau of Meteorology 2012). It is possible that the sustained reduction in dolphin density is a result of emigration because of the thermal forcing from the heat wave itself. We think this unlikely, however, because the range of Tursiops aduncus extends far into tropical waters where sea temperatures regularly meet or exceed those encountered at the height of the marine heat wave in Shark Bay.

Tursiops aduncus within the study area have relatively stable home ranges, high philopatry, and inter-individual social bonds that likely play critical roles in reproductive success and fitness (e.g., Smolker et al. 1992, Connor et al. 2001, Krützen et al. 2004, Tsai and Mann 2013). Dolphins are thus likely to remain in the system as long as adequate resources are available. However, abnormal dolphin mortality was not observed during the course of this study or by a contemporary study of mother-calf pairs (Miketa 2018), making it difficult to explain the declines observed here. While dolphins in Shark Bay forage on seagrass-associated fishes, they are less dependent on seagrass for forage than cormorants or sea snakes (Heithaus and Dill 2002, Heithaus 2004, Sargeant et al. 2007, Heithaus et al. 2013).

\section{Drivers of mesoconsumer habitat use patterns following seagrass loss}

Myriad factors can influence consumer habitat use, including resource availability, consumer body condition, social factors, physiological effects, and predation risk (Fretwell and Lucas 1969, Clark 1994, Heithaus et al. 2009). Following the seagrass die-off, we observed shifts in habitat use by several species, though habitat shifts consistent with increased risk taking were only observed in bottlenose dolphins. These results highlight the complex nature of species responses to resource loss and emphasize the role of multiple drivers in species-specific disturbance response.

Changes in food supply.- The impact of seagrass loss on food supplies of air-breathing megafauna in this system is likely species specific, and in some cases may be counterintuitive. Net loss of seagrass biomass represents an obvious system-wide food reduction for seagrass herbivores, including dugongs and some green turtles, though expansion by tropical seagrasses in the wake of Amphibolis declines (Nowicki et al. 2017) may soften this loss. 
However, while the extent of seagrass on shallow banks has been reduced, these banks still represent relatively "resource rich" habitats when compared to seagrass depauperate deep channels. Herbivores that rely on seagrass directly may therefore be forced to continue to spend time in remaining seagrass habitats, even if predation risk in those habitats has increased. This appears to be the case with dugongs, which increased relative use of shallow habitats consistently across shark CPUE following the seagrass die-off (Fig. 5).

Species that rely on seagrass associated prey are likely to exhibit more complex responses to massive seagrass loss. Piscivorous air-breathing megafauna (sea snakes, Cormorants, dolphins) have likely experienced a net reduction in food supply driven by reduced teleost fish biomass in shallow habitats (R. Nowicki et al., unpublished data). However, reductions of absolute food supply may be offset somewhat by increased teleost density in remaining vegetated habitats post-die-off ( $\mathrm{R}$. Nowicki et al., unpublished data), and through reduced refuge for teleosts and increased echolocation and foraging efficiency in newly denuded habitats (Wilson et al. 2013, Miketa 2018). For example, a contemporary study in Shark Bay indicated that while seagrass associated dolphins used seagrass habitats more frequently after the heat wave, they reduced their foraging time in heavily damaged beds, instead foraging in relatively intact seagrass habitats (Miketa 2018). Similarly, cormorants in this system track prey densities even at fine, microhabitat scales (Heithaus 2005), and cormorants were more likely to use shallow habitats after the seagrass die-off. Changes in cormorant foraging efficiency may drive this shift in habitat use independent of shark abundance.

Loggerhead turtles increased their relative use of shallow habitats regardless of shark catch rate after the seagrass die-off. This shift, combined with the lack of numerical response to the seagrass die-off, suggest that as with tiger sharks, seagrass loss may be at least temporarily advantageous for this species. In Shark Bay, loggerhead turtles are most commonly found, and appear to forage most often, in unvegetated habitats where they can locate and consume both epibenthic and infaunal invertebrates more easily (Thomson et al. 2012b). Loggerhead turtles are also known to scavenge opportunistically and to have broad diets at both the individual and population level (Plotkin et al. 1993, Tomas et al. 2001, Casale et al. 2008, Thomson et al. 2012b). Unfortunately, time series data on bivalve abundance and density were not available to test changes in food availability for this species in our study area. In general, stocks of both saucer scallops (Amusium balloti) and blue swimmer crabs (Portunus armatus) suffered heavy declines in the region following 2011, which has been attributed to both direct effects (temperature related mortality) and indirect legacy effects (seagrass loss) associated with the heat wave (Caputi et al. 2014). As with dolphins and cormorants, however, it is plausible that newly denuded seagrass habitats yield reduced search time, increased prey encounter rates, or increased turtle foraging success, especially given the capability of loggerhead turtles to scavenge. This would explain shifts in loggerhead turtle habitat use since the seagrass die-off.

Changes to predation risk. - Because tiger sharks dominated the catch both before and after the die-off, we inferred that warm periods remain risky to tiger shark prey at the ecosystem scale, whereas most winters remain relatively safe. Thus, the broad temporal pattern of predation risk that typified this system and drove shifts in prey habitat use patterns prior to the heat wave (Heithaus et al. 2012 and references therein) likely remains fundamentally unchanged despite massive resource loss. However, predation risk is mediated in part by factors other than predator abundance and encounter rate, such as likelihood of detection of both predator and prey and escape probability (Lima and Dill 1990), which are in turn mediated by properties of predators, prey, the environment, and higher order interactions (Clark 1994, Heithaus et al. 2007c, 2009, Wirsing et al. 2010). Furthermore, anti-predator behavior is also balanced with other needs, such as the need to forage. Therefore, changes to other drivers of predation risk may alter the role of tiger shark predation and top down control in this ecosystem.

Reduced water clarity associated with the die-off (Nowicki et al. 2017) may alter predator-prey interactions by reducing the efficacy of both antipredator behavior (i.e., vigilance, flight initiation) and prey detection by predators. This may result in an altered risk landscape and changes to megafauna antipredator behavior, even for species that do not directly rely on vegetation to reduce predation risk. For example, dugongs, cormorants, and green turtles minimize predation risk by detecting predators early and either fleeing from or outmaneuvering them (Heithaus et al. 2012), and at least some of these escape maximizers avoid profitable behaviors if those behaviors reduce visibility (Wirsing et al. 2007a). This may result in changes to net top-down control, or in the relative importance of direct predation and predation risk to the fitness of these consumers, even if predator abundance has remained constant.

Although decreased visibility is likely to increase predation risk for visually dependent escape maximizers, other prey may benefit from reduced visibility if the effective prey detection radius of tiger sharks is reduced. Loggerhead turtles, for example, rely on a thick, rounded shell instead of speed to survive predator encounters (Heithaus et al. 2002, 2008), an antipredator strategy that may be relatively insensitive to reduced water clarity. Reduced water clarity may alter predation risk on bottlenose dolphins by changing the relative importance of visual and non-visual cues among dolphins and sharks alike. Because dolphins in this system use seagrass banks primarily for foraging and move to deeper areas for resting (Heithaus and Dill 2002), the observed pattern of 
increased proportional use of risky interior habitats by dolphins is consistent with several potential (and nonexclusive) drivers, including individuals taking greater risks to obtain foraging rewards because of reduced energetic state and changes in foraging success in remaining seagrass habitats.

Though tiger shark abundance has not changed, changes in dolphin habitat use patterns could also potentially owe to spatial shifts in tiger shark habitat use patterns within the study system. Whereas we were unable to robustly assess microhabitat use patterns of tiger sharks in the study system after the seagrass die-off, in part because logistical constraints (high rates of bait loss) prevent shark fishing in shallow habitats (Heithaus 2001), we think that this explanation is unlikely. Video and active acoustic tracking of sharks before the die-off revealed that tiger sharks spend more time in shallow than deep habitats (Heithaus et al. 2002, 2006). With the increased use of shallow habitats by bottlenose dolphins, cormorants, and loggerhead turtles, it seems unlikely that tiger sharks would reverse previous habitat preferences to instead target deep habitats. Even if tiger sharks have shifted to using shallow habitats less frequently (and reducing shark encounter rates experienced by prey), encounter probability is only one component of predation risk (Lima and Dill 1990, Heithaus et al. 2009), and habitat types can carry intrinsic risk that can alter prey behavior (reviewed in Laundré et al. 2010) Indeed, shallow habitats reduce the vertical maneuverability potential (and thus escape potential) for dugongs (Wirsing et al. 2007c), dolphins (Heithaus and Dill 2002, 2006), and green turtles (Heithaus et al. 2007a), further supporting the notion that tiger sharks should continue to prefer shallow habitats.

Synthesis and broader ecological implications. - Whereas studies manipulating resources, predator, and prey are relatively tractable in terrestrial systems, they are rarely feasible in marine systems, particularly at landscape and community scales. The Ningaloo Niño of 2011 offered a rare opportunity to observe the direct and indirect effects of an extreme climatic event (ECE) on a relatively pristine marine ecosystem at large scales and across multiple trophic levels.

Because direct and indirect effects of ECEs operate through different pathways (i.e., physical forcing vs. resource loss), fauna that are resilient to one kind of effect may still succumb to ECEs through the other. For example, while direct abiotic effects of the Ningaloo Niño were likely uniformly negligible on the populations studied here, indirect effects varied substantially. In agreement with theory and results found in other systems, resource loss most strongly affected specialists, while generalist consumers like tiger sharks and loggerhead turtles remained relatively stable. Unsurprisingly, population declines were highest among species most reliant on seagrasses: dugongs, which are obligate seagrass herbivores, and sea snakes, which rely on seagrass beds both as a hunting ground and a refuge from their own predators. These patterns reflect differential sensitivity and adaptive capacity to resource loss, two of the components predicted to influence climate vulnerability (Butt et al. 2016).

While tiger sharks were resilient to the ECE as a tropical generalist predator, a temperate generalist predator may have experienced large population declines from direct physical forcing, even if legacy effects would have been minimal. As such, overall vulnerability to ECEs may be broadly predictable if one has information about both a species' physiological constraints and its resource use patterns. Assessments of the vulnerability of consumers to ECEs should therefore incorporate vulnerability to both direct and indirect effects. Furthermore, we demonstrate and caution that just because one pathway has little effect on an assemblage does not guarantee negligible overall effects.

In the absence of direct mortality evidence (such as strandings), it is reasonable to conclude that the mechanism of population decline is likely mediated by dispersal capacity, with low dispersers (like sea snakes) succumbing to mortality and more mobile species like dugongs and cormorants emigrating from the system. This has strong implications for both future population and community dynamics of these species and for the resilience of these populations to future stressors, but needs to be further tested.

A growing number of studies demonstrate that ECEs can have fundamental and lasting effects on marine communities by killing primary producers and altering subsequent species interactions between consumers and producers (e.g., Vergés et al. 2014, Bennett et al. 2015). This illustrates the importance of predicting when and how the direct and indirect effects of extreme events strengthen or weaken top-down control. Changes to the strength and nature of top-down control are likely when disturbance impacts affect different trophic levels unequally and may be mediated by several non-exclusive pathways. First, prey that are energetically stressed are less able to heed predation risk, often resulting in an increase in the relative importance of direct predation. Indeed, both theory and empirical work indicate that resource limitation can mediate the effects of top down control on plant communities through both direct predation and predation risk (Oksanen et al. 1981, Clark 1994, Chase 1996, Werner and Peacor 2006, Heithaus et al. 2007a, Schmitz 2010). Second, changes in the food landscape may change the spatial component of food for safety trade-offs, even if predators populations remain similar. Finally, changes in the physical landscape, such as defoliation and reductions in water clarity, may alter predation risk and direct predation by modifying encounter, attack, and escape rates. These factors in combination make predicting specific changes to predator-prey dynamics challenging. Nonetheless, our data show that in at least some cases, ECEs can change 
predation risk dynamics through legacy effects, even when predator populations remain constant.

In conclusion, we argue that a better understanding and prediction of the ecological impacts of ECEs is necessary, and can be obtained through explicit recognition that (1) ECEs generate both direct and indirect effects, which operate via different pathways; (2) a consumer's resilience to one pathway does not inherently convey resilience to the other; (3) first-order predictions about vulnerabilities to ECEs are likely possible given knowledge of a consumer's physiological tolerances and resource use patterns; and (4) ECEs will almost certainly affect different trophic levels unequally, which when combined with changes in landscape may fundamentally alter predator/prey dynamics even if one or both populations remain similar after an ECE occurs. We advocate for greater integration of predator-prey theory and disturbance ecology in the development of frameworks designed to predict how ecosystems will respond to the myriad anthropogenic stressors they face now and in the future. To our knowledge, this is among the first studies to investigate the legacy effects of an ECE on the abundance and habitat use of such a wide variety of marine consumers at the ecosystem scale, and represents a small but important step in integrating disturbance ecology and predator-prey ecology.

\section{ACKNOWLEDGMENTS}

The authors would like to acknowledge the critical assistance of dozens of SBERP field personnel and visiting researchers who helped collect field data but are too numerous to name individually here. We also thank the people of Monkey Mia Dolphin Resort and Shark Bay for considerable logistical support, as well as Blanche D'Anastasi for guidance on sea snake biology and Jeremy Vaudo for guidance on initial analysis of shark catch data. All authors contributed significantly to data collection, field operations, manuscript preparation, and project development. In addition, R. J. Nowicki collated and analyzed the data, provided material support, created the figures, and wrote the manuscript; M. R. Heithaus initiated the project, led project development, and provided material support. Financial support was provided by donations from the public, NSF grants OCE0745606 and OCE1329408 awarded to M. R. Heithaus, as well as an NSF Graduate Research Fellowship (DGE-1038321), FIU Dissertation Year Fellowship, PADI foundation award, and Mote Postdoctoral Research Fellowship to R. J. Nowicki. This is contribution No. 86 to the Shark Bay Ecosystem Research Project and No. 128 from the Center for Coastal Oceans Research in the Institute of Water and Environment at FIU.

\section{Literature Cited}

Anderson, P. K. 1986. Dugongs of Shark Bay, Australia-seasonal migration, water temperature, and forage. National Geographic Research 2:473-490.

Bates, D., M. Maechler, B. Bolker, and S. Walker. 2015. Fitting linear mixed-effects models using lme4. Journal of Statistical Software 67:1-48.

Bennett, S., T. Wernberg, E. S. Harvey, J. Santana-Garcon, and B. J. Saunders. 2015. Tropical herbivores provide resilience to a climate-mediated phase shift on temperate reefs. Ecology Letters 18:714-723.
Bessey, C., M. R. Heithaus, J. W. Fourqurean, K. R. Gastrich, and D. A. Burkholder. 2016. Importance of teleost macrograzers to seagrass composition in a subtropical ecosystem with abundant populations of megagrazers and predators. Marine Ecology Progress Series 553:81-92.

Breshears, D. D., et al. 2005. Regional vegetation die-off in response to global-change-type drought. Proceedings of the National Academy of Sciences of the United States of America 102:15144-15148.

Brooks, M. E., K. Kristensen, K. J. van Benthem, A. Magnusson, C. W. Berg, A. Nielsen, H. J. Skaug, M. Maechler, and B. M. Bolker. 2017. glmmTMB balances speed and flexibility among packages for zero-inflated generalized linear mixed modeling. R Journal 9:378-400.

Bureau of Meterology. 2012. Record-breaking La Nina events: An analysis of the La Nina life cycle and the impacts and significance of the 2010-11 and 2011-12 La Nina events in Australia. Bureau of Meterology, Melbourne, Victoria. Pages 28.

Burkholder, D. A., M. R. Heithaus, J. A. Thomson, and J. W. Fourqurean. 2011. Diversity in trophic interactions of green sea turtles Chelonia mydas on a relatively pristine coastal foraging ground. Marine Ecology Progress Series 439:277-293.

Burkholder, D. A., M. R. Heithaus, J. W. Fourqurean, A. Wirsing, and L. M. Dill. 2013a. Patterns of top-down control in a seagrass ecosystem: could a roving apex predator induce a behaviour-mediated trophic cascade? Journal of Animal Ecology 82:1192-1202.

Burkholder, D. A., J. W. Fourqurean, and M. R. Heithaus. 2013b. Spatial pattern in seagrass stoichiometry indicates both N-limited and P-limited regions of an iconic P-limited subtropical bay. Marine Ecology Progress Series 472:101115 .

Burns, G., and H. Heatwole. 1998. Home range and habitat use of the olive sea snake, Aipysurus laevis, on the Great Barrier Reef, Australia. Journal of Herpetology 32:350-358.

Butt, N., H. P. Possingham, C. De Los Rios, R. Maggini, R. A. Fuller, S. L. Maxwell, and J. E. M. Watson. 2016. Challenges in assessing the vulnerability of species to climate change to inform conservation actions. Biological Conservation 199:10-15.

Cahill, A. E., et al. 2013. How does climate change cause extinction? Proceedings of the Royal Society B: Biological Sciences 280:20121890.

Cai, W., et al. 2014. Increasing frequency of extreme El Niño events due to greenhouse warming. Nature Climate Change 4:111-116.

Cai, W., et al. 2015. Increased frequency of extreme La Niña events under greenhouse warming. Nature Climate Change 5:132-137.

Cannell, B. L., L. E. Chambers, R. D. Wooller, and J. S. Bradley. 2012. Poorer breeding by little penguins near Perth, Western Australia is correlated with above average sea surface temperatures and a stronger Leeuwin Current. Marine and Freshwater Research 63:914-925.

Caputi, N., G. Jackson, and A. Pearce. 2014. The marine heat wave off Western Australia during the summer of 2010/11: 2 years on. Fisheries Research Division, Western Australian Fisheries and Marine Research Laboratories, North Beach, Western Australia.

Casale, P., G. Abbate, D. Freggi, N. Conte, M. Oliverio, and R. Argano. 2008. Foraging ecology of loggerhead sea turtles Caretta caretta in the central Mediterranean Sea: evidence for a relaxed life history model. Marine Ecology Progress Series 372:265-276.

Castro, J. I. 2010. The sharks of North America. Oxford University Press, New York, New York, USA.

Chapman, S., K. Mustin, A. R. Renwick, D. B. Segan, D. G. Hole, R. G. Pearson, and J. E. M. Watson. 2014. Publishing 
trends on climate change vulnerability in the conservation literature reveal a predominant focus on direct impacts and long time-scales. Diversity and Distributions 20:1221-1228.

Chase, J. M. 1996. Abiotic controls of trophic cascades in a simple grassland food chain. Oikos 77:495-506.

Clark, C. W. 1994. Antipredator behavior and the asset-protection principle. Behavioral Ecology 5:159-170.

Connor, R. C., M. R. Heithaus, and L. M. Barre. 2001. Complex social structure, alliance stability and mating access in a bottlenose dolphin "super-alliance". Proceedings of the Royal Society B 268:263-267.

Costanza, R., et al. 1997. The value of the world's ecosystem services and natural capital. Nature 387:253.

Creel, S., and D. Christianson. 2008. Relationships between direct predation and risk effects. Trends in Ecology \& Evolution 23:194-201.

Creel, S., D. A. Christianson, and J. A. Winnie. 2011. A survey of the effects of wolf predation risk on pregnancy rates and calf recruitment in elk. Ecological Applications 21:28472853.

Dell, J., and S. Cherriman. 2008. The birds of Faure Island, Shark Bay, Western Australia. Records of the Western Australian Museum Supplement No, 75, 70.

Department of Environment and Conservation. 2008. Shark Bay World Heritage Property strategic plan, 2008-2020. Department of Environment and Conservation, Perth, Western Australia, Australia.

DiBattista, J. D., K. A. Feldheim, D. Garant, S. H. Gruber, and A. P. Hendry. 2011. Anthropogenic disturbance and evolutionary parameters: a lemon shark population experiencing habitat loss. Evolutionary Applications 4:1-17.

Dill, L. M., M. R. Heithaus, and C. J. Walters. 2003. Behaviorally mediated indirect interactions in marine communities and their conservation implications. Ecology 84:1151-1157.

Dunn, P. K. 2017. Tweedie: Evaluation of Tweedie exponential family models. $\mathrm{R}$ package version 2.3 .

Ferreira, L. C., M. Thums, J. J. Meeuwig, G. M. S. Vianna, J. Stevens, R. McAuley, and M. G. Meekan. 2015. Crossing latitudes-long-distance tracking of an apex predator. PLoS ONE 10:e0116916.

Ferreira, L. C., et al. 2017. The trophic role of a large marine predator, the tiger shark Galeocerdo cuvier. Scientific Reports 7:7641.

Fourqurean, J. W., et al. 2012. Seagrass ecosystems as a globally significant carbon stock. Nature Geoscience 5:505-509.

Fraser, M. W., G. A. Kendrick, J. Statton, R. K. Hovey, A. Zavala-Perez, and D. I. Walker. 2014. Extreme climate events lower resilience of foundation seagrass at edge of biogeographical range. Journal of Ecology 102:1528-1536.

Fretwell, S. D., and H. J. Lucas Jr. 1969. On territorial behaviour and other factors influencing habitat distribution of birds. Acta Biotheoretica 19:19-36.

Fury, C. A., and P. L. Harrison. 2011. Impact of flood events on dolphin occupancy patterns. Marine Mammal Science 27: E185-E205.

Gales, N., R. D. McCauley, J. Lanyon, and D. Holley. 2004. Change in abundance of dugongs in Shark Bay, Ningaloo and Exmouth Gulf, Western Australia: evidence for largescale migration. Wildlife Research 31:283-290.

Giner, G., and G. K. Smyth. 2016. statmod: probability calculations for the inverse Gaussian distribution. R Journal 8:339351.

Great Barrier Reef Marine Park Authority. 2014. Great Barrier Reef outlook report 2014. GBRMPA, Townsville.

Hartig, F. 2017. DHARMa: Residual Diagnostics for Hierarchical (Multi-Level/Mixed) Regression Models. R package version
0.1.6. https://cran.r-project.org/web/packages/DHARMa/index. html

Heck, K. L., G. Hays, and R. J. Orth. 2003. Critical evaluation of the nursery role hypothesis for seagrass meadows. Marine Ecology Progress Series 253:123-136.

Heithaus, M. R. 2001. The biology of tiger sharks, Galeocerdo cuvier, in Shark Bay, Western Australia: sex ratio, size distribution, diet, and seasonal changes in catch rates. Environmental Biology of Fishes 61:25-36.

Heithaus, M. R. 2004. Fish communities of subtropical seagrass meadows and associated habitats in Shark Bay, Western Australia. Bulletin of Marine Science 75:79-99.

Heithaus, M. R. 2005. Habitat use and group size of pied cormorants (Phalacrocorax varius) in a seagrass ecosystem: possible effects of food abundance and predation risk. Marine Biology 147:27-35.

Heithaus, M. R., and L. M. Dill. 2002. Food availability and tiger shark predation risk influence bottlenose dolphin habitat use. Ecology 83:480-491.

Heithaus, M. R., and L. M. Dill. 2006. Does tiger shark predation risk influence foraging habitat use by bottlenose dolphins at multiple spatial scales? Oikos 114:257-264.

Heithaus, M. R., L. Dill, G. J. Marshall, and B. Buhleier. 2002. Habitat use and foraging behavior of tiger sharks (Galeocerdo cuvier) in a seagrass ecosystem. Marine Biology 140:237-248.

Heithaus, M. R., A. Frid, A. J. Wirsing, L. M. Dill, J. W. Fourqurean, D. Burkholder, J. Thomson, and L. Bejder. 2007a. State-dependent risk-taking by green sea turtles mediates topdown effects of tiger shark intimidation in a marine ecosystem. Journal of Animal Ecology 76:837-844.

Heithaus, M. R., A. Frid, A. J. Wirsing, and B. Worm. 2008. Predicting ecological consequences of marine top predator declines. Trends in Ecology \& Evolution 23:202-210.

Heithaus, M. R., I. M. Hamilton, A. J. Wirsing, and L. M. Dill. 2006. Validation of a randomization procedure to assess animal habitat preferences: microhabitat use of tiger sharks in a seagrass ecosystem. Journal of Animal Ecology 75:666-676.

Heithaus, M. R., A. J. Wirsing, D. Burkholder, J. Thomson, and L. M. Dill. 2009. Towards a predictive framework for predator risk effects: the interaction of landscape features and prey escape tactics. Journal of Animal Ecology 78:556562.

Heithaus, M. R., A. J. Wirsing, L. M. Dill, and L. I. Heithaus. 2007b. Long-term movements of tiger sharks satellite-tagged in Shark Bay, Western Australia. Marine Biology 151:14551461.

Heithaus, M. R., A. J. Wirsing, A. Frid, and L. M. Dill. $2007 c$. Behavioral indicators in marine conservation: lessons from a pristine seagrass ecosystem. Israel Journal of Ecology \& Evolution 53:355-370.

Heithaus, M. R., A. J. Wirsing, and L. M. Dill. 2012. The ecological importance of intact top-predator populations: a synthesis of 15 years of research in a seagrass ecosystem. Marine and Freshwater Research 63:1039-1050.

Heithaus, M. R., et al. 2013. Apparent resource partitioning and trophic structure of large-bodied marine predators in a relatively pristine seagrass ecosystem. Marine Ecology Progress Series 481:225-237.

Heupel, M. R., C. A. Simpfendorfer, and R. E. Hueter. 2003. Running before the storm: blacktip sharks respond to falling barometric pressure associated with Tropical Storm Gabrielle. Journal of Fish Biology 63:1357-1363.

Hobday, A. J., et al. 2016. A hierarchical approach to defining marine heatwaves. Progress in Oceanography 141:227-238.

Hodgson, A. 2007. The distribution, abundance and conservation of dugongs and other marine megafauna in Shark Bay Marine Park, Ningaloo Reef Marine Park and Exmouth 
Gulf. Department of Environment and Conservation, St Lucia, Queensland.

Holley, D. 2006. Movement patterns and habitat usage of Shark Bay dugongs. Dissertation. Edith Cowan University, Perth, Western Australia, Australia.

Jeffries, M. J., and J. H. Lawton. 1984. Enemy free space and the structure of ecological communities. Biological Journal of the Linnean Society 23:269-286.

Jennings, D. E., S. H. Gruber, B. R. Franks, S. T. Kessel, and A. L. Robertson. 2008. Effects of large-scale anthropogenic development on juvenile lemon shark (Negaprion brevirostris) populations of Bimini, Bahamas. Environmental Biology of Fishes 83:369-377.

Jentsch, A., J. Kreyling, and C. Beierkuhnlein. 2007. A new generation of climate-change experiments: events, not trends. Frontiers in Ecology and the Environment 5:365-374.

Jones, C. G., J. H. Lawton, and M. Shachak. 1994. Organisms as ecosystem engineers. Oikos 69:373-386.

Kerford, M. R., A. J. Wirsing, M. R. Heithaus, and L. M. Dill. 2008. Danger on the rise: diurnal tidal state mediates an exchange of food for safety by the bar-bellied sea snake Hydrophis elegans. Marine Ecology Progress Series 358:289-294.

Krützen, M., W. B. Sherwin, P. Berggren, and N. Gales. 2004 Population structure in an inshore cetacean revealed by microsatellite and mtDNA analysis: bottlenose dolphins (Tursiops sp.) in Shark Bay, Western Australia. Marine Mammal Science 20:28-47.

Langtimm, C. A., and C. A. Beck. 2003. Lower survival probabilities for adult Florida manatees in years with intense coastal storms. Ecological Applications 13:257-268.

Laundré, J. W., L. Hernández, and W. J. Ripple. 2010. The landscape of fear: ecological implications of being afraid. Open Ecology Journal 3:1-7.

Lima, S. L. 1998. Nonlethal effects in the ecology of predatorprey interactions. BioScience 48:25-34.

Lima, S. L., and L. M. Dill. 1990. Behavioral decisions made under the risk of predation: a review and prospectus. Canadian Journal of Zoology 68:619-640.

Loneragan, N., et al. 2003. Developing techniques for enhancing prawn fisheries, with a focus on brown tiger prawns (Penaeus esculentus) in Exmouth Gulf. Final Report on FRDC Project 1999/222. CSIRO, Cleveland, Ohio, USA.

Lowe, C. G., B. M. Wetherbee, G. L. Crow, and A. L. Tester. 1996. Ontogenetic dietary shifts and feeding behavior of the tiger shark, Galeocerdo cuvier, in Hawaiian waters. Environmental Biology of Fishes 47:203-211.

Lukoschek, V., and R. Shine. 2012. Sea snakes rarely venture far from home. Ecology and Evolution 2:1113-1121.

Lukoschek, V., M. Waycott, and J. S. Keogh. 2008. Relative information content of polymorphic microsatellites and mitochondrial DNA for inferring dispersal and population genetic structure in the olive sea snake, Aipysurus laevis. Molecular Ecology 17:3062-3077.

Marsh, H. E. 1989. Mass stranding of dugongs by a tropical cyclone in northern Australia. Marine Mammal Science 5:78-84.

Marsh, H., P. W. Channells, G. E. Heinsohn, and J. Morrissey. 1982. Analysis of stomach contents of dugongs from Queensland. Wildlife Research 9:55-67.

Matich, P., and M. R. Heithaus. 2012. Effects of an extreme temperature event on the behavior and age structure of an estuarine top predator, Carcharhinus leucas. Marine Ecology Progress Series 447:165-178.

Matich, P., M. R. Heithaus, and C. A. Layman. 2011. Contrasting patterns of individual specialization and trophic coupling in two marine apex predators. Journal of Animal Ecology 80:294-305
McKenzie, L. J., C. Collier, and M. Waycott. 2012. Reef rescue marine monitoring program - inshore seagrass, annual report for the sampling period 1st July 2010-31st May 2011. Fisheries Queensland, Cairns, Queensland, Australia.

Miketa, M. L. 2018. Social and Behavioral Responses to Environmental Stressors in Bottlenose Dolphins in Shark Bay, Australia. Dissertation. Georgetown University, Washington, D.C., USA.

Nowicki, R. J., J. A. Thomson, D. A. Burkholder, and J. W. Fourqurean. 2017. Predicting seagrass recovery trajectories and their implications following an extreme climate event. Marine Ecology Progress Series 567:79-93.

Ockendon, N., et al. 2014. Mechanisms underpinning climatic impacts on natural populations: altered species interactions are more important than direct effects. Global Change Biology 20:2221-2229.

Oksanen, L., S. D. Fretwell, J. Arruda, and P. Niemela. 1981. Exploitation ecosystems in gradients of primary productivity. American Naturalist 118:240-261.

Oliver, E. C. J., J. A. Benthuysen, N. L. Bindoff, A. J. Hobday, N. J. Holbrook, C. N. Mundy, and S. E. Perkins-Kirkpatrick. 2017. The unprecedented 2015/16 Tasman Sea marine heatwave. Nature Communications 8:16101.

Oliver, E. C. J., et al. 2018. Longer and more frequent marine heatwaves over the past century. Nature Communications 9:1324.

Orth, R. J., et al. 2006. A global crisis for seagrass ecosystems. BioScience 56:987-996.

Pachauri, R. K., et al. 2014. Climate change 2014: synthesis report. Contribution of working groups I, II and III to the fifth assessment report of the intergovernmental panel on climate change. IPCC, Geneva, Switzerland.

Paine, R. T. 1980. Food webs: linkage, interaction strength and community infrastructure. Journal of Animal Ecology 49:667-685.

Paine, R. T. 1992. Food-web analysis through field measurement of per capita interaction strength. Nature 355:73.

Pearce, A. F., and M. Feng. 2013. The rise and fall of the "marine heat wave" off Western Australia during the summer of 2010/2011. Journal of Marine Systems 111:139-156.

Plotkin, P. T., M. K. Wicksten, and A. F. Amos. 1993. Feeding ecology of the loggerhead sea turtle Caretta caretta in the Northwestern Gulf of Mexico. Marine Biology 115:1-5.

Power, M. E., D. Tilman, J. A. Estes, B. A. Menge, W. J. Bond, L. S. Mills, G. Daily, J. C. Castilla, J. Lubchenco, and R. T. Paine. 1996. Challenges in the quest for keystones. BioScience 46:609-620.

Preen, A. 1995. Impacts of dugong foraging on seagrass habitats: observational and experimental evidence for cultivation grazing. Marine Ecology Progress Series 124:201-213.

Preen, A., and H. Marsh. 1995. Response of dugongs to largescale loss of seagrass from Hervey Bay, Queensland, Australia. Wildlife Research 22:507-519.

Ripple, W. J., and R. L. Beschta. 2004. Wolves and the ecology of fear: can predation risk structure ecosystems? BioScience 54:755-766.

RStudio Team. 2015. RStudio: integrated development for R. RStudio, Boston, Massachusetts, USA

Ryall, K. L., and L. Fahrig. 2006. Response of predators to loss and fragmentation of prey habitat: a review of theory. Ecology 87:1086-1093.

Sanders-DeMott, R., R. McNellis, M. Jabouri, and P. H. Templer. 2018. Snow depth, soil temperature, and plant-herbivore interactions mediate plant response to climate change. Journal of Ecology 106:1508-1519.

Sargeant, B. L., A. J. Wirsing, M. R. Heithaus, and J. Mann. 2007. Can environmental heterogeneity explain individual 
foraging variation in wild bottlenose dolphins (Tursiops sp.)? Behavioral Ecology and Sociobiology 61:679-688.

Schmitz, O. J. 2010. Resolving ecosystem complexity (MPB-47). Princeton University Press, Princeton, New Jersey, USA.

Schmitz, O. J., A. P. Beckerman, and K. M. O’Brien. 1997. Behaviorally mediated trophic cascades: effects of predation risk on food web interactions. Ecology 78:1388-1399.

Seney, E. E., and J. A. Musick. 2007. Historical diet analysis of loggerhead sea turtles (Caretta caretta) in Virginia. Copeia 2007:478-489.

Sheppard, J. K., A. R. Preen, H. Marsh, I. R. Lawler, S. D. Whiting, and R. E. Jones. 2006. Movement heterogeneity of dugongs, Dugong dugon (Müller), over large spatial scales. Journal of Experimental Marine Biology and Ecology 334:64-83.

Short, F. T., and S. Wyllie-Echeverria. 1996. Natural and human-induced disturbance of seagrasses. Environmental Conservation 23:17-27.

Sinclair, A. R. E., and R. P. Pech. 1996. Density dependence, stochasticity, compensation and predator regulation. Oikos $75: 164-173$

Smith, M. D. 2011a. The ecological role of climate extremes: current understanding and future prospects. Journal of Ecology 99:651-655.

Smith, M. D. 2011b. An ecological perspective on extreme climatic events: a synthetic definition and framework to guide future research. Journal of Ecology 99:656-663.

Smolker, R. A., A. F. Richards, R. C. Connor, and J. W. Pepper. 1992. Sex differences in patterns of association among Indian Ocean bottlenose dolphins. Behaviour 123:38-69.

Sprogis, K. R., F. Christiansen, M. Wandres, and L. Bejder. 2018. El Niño Southern Oscillation influences the abundance and movements of a marine top predator in coastal waters. Global Change Biology 24:1085-1096.

Taylor, S. A., E. L. Larson, and R. G. Harrison. 2015. Hybrid zones: windows on climate change. Trends in Ecology \& Evolution 30:398-406.

Thomson, J., A. Cooper, D. Burkholder, M. Heithaus, and L. Dill. 2012a. Heterogeneous patterns of availability for detection during visual surveys: spatiotemporal variation in sea turtle dive-surfacing behaviour on a feeding ground. Methods in Ecology and Evolution 3:378-387.

Thomson, J. A., M. R. Heithaus, D. A. Burkholder, J. J. Vaudo, A. J. Wirsing, and L. M. Dill. 2012b. Site specialists, diet generalists? Isotopic variation, site fidelity, and foraging by loggerhead turtles in Shark Bay, Western Australia. Marine Ecology Progress Series 453:213-226.

Thomson, J. A., A. B. Cooper, D. A. Burkholder, M. R. Heithaus, and L. M. Dill. 2013. Correcting for heterogeneous availability bias in surveys of long-diving marine turtles. Biological Conservation 165:154-161.

Thomson, J. A., D. A. Burkholder, M. R. Heithaus, J. W. Fourqurean, M. W. Fraser, J. Statton, and G. A. Kendrick. 2014. Extreme temperatures, foundation species, and abrupt ecosystem change: an example from an iconic seagrass ecosystem. Global Change Biology 21:1463-1474.

Thomson, J. A., E. R. Whitman, M. I. Garcia-Rojas, A. Bellgrove, M. Ekins, G. C. Hays, and M. R. Heithaus. 2018. Individual specialization in a migratory grazer reflects long-term diet selectivity on a foraging ground: implications for isotopebased tracking. Oecologia 188:429-439.

Tomas, J., F. J. Aznar, and J. A. Raga. 2001. Feeding ecology of the loggerhead turtle Caretta caretta in the western Mediterranean. Journal of Zoology 255:525-532.

Tsai, Y. J. J., and J. Mann. 2013. Dispersal, philopatry, and the role of fission-fusion dynamics in bottlenose dolphins. Marine Mammal Science 29:261-279.
Tweedie, M. C. K. 1984. An index which distinguishes between some important exponential families. In Statistics: Applications and new directions. Proceedings of the Indian Statistical Institute Golden Jubilee International Conference. Volume 579. Indian Statistical Institute, Calcutta, India.

Udyawer, V., A. Chin, D. M. Knip, C. A. Simpfendorfer, and M. R. Heupel. 2013. Variable response of coastal sharks to severe tropical storms: environmental cues and changes in space use. Marine Ecology Progress Series 480:171-183.

Unsworth, R. K., L. M. Nordlund, and L. C. Cullen-Unsworth. 2018. Seagrass meadows support global fisheries production. Conservation Letters 12:e12566.

Vergés, A., et al. 2014. The tropicalization of temperate marine ecosystems: climate-mediated changes in herbivory and community phase shifts. Proc. R. Soc. B 281:20140846.

Walker, D. I. 1985. Correlations between salinity and growth of the seagrass Amphibolis antarctica (Labill.) Sonder \& Aschers., in Shark Bay, Western Australia, using a new method for measuring production rate. Aquatic Botany 23:13-26.

Walker, D. I., and A. J. McComb. 1988. Seasonal variation in the production, biomass and nutrient status of Amphibolis antarctica (Labill.) Sonder ex Aschers. and Posidonia australis Hook. f. in Shark Bay, Western Australia. Aquatic Botany 31:259-275.

Walker, D. I., G. A. Kendrick, and A. J. McComb. 1988. The distribution of seagrass species in Shark Bay, Western Australia, with notes on their ecology. Aquatic Botany 30:305317.

Waycott, M., et al. 2009. Accelerating loss of seagrasses across the globe threatens coastal ecosystems. Proceedings of the National Academy of Sciences USA 106:12377-12381.

Wernberg, T., D. A. Smale, F. Tuya, M. S. Thomsen, T. J. Langlois, T. De Bettignies, S. Bennett, and C. S. Rousseaux. 2013. An extreme climatic event alters marine ecosystem structure in a global biodiversity hotspot. Nature Climate Change 3:78-82.

Werner, E. E., and S. D. Peacor. 2003. A review of traitmediated indirect interactions in ecological communities. Ecology 84:1083-1100.

Werner, E. E., and S. D. Peacor. 2006. Lethal and nonlethal predator effects on an herbivore guild mediated by system productivity. Ecology 87:347-361.

Wilson, C. J., P. S. Wilson, C. A. Greene, and K. H. Dunton. 2013. Seagrass meadows provide an acoustic refuge for estuarine fish. Marine Ecology Progress Series 472:117-127.

Wirsing, A. J., and M. R. Heithaus. 2009. Olive-headed sea snakes Disteria major shift seagrass microhabitats to avoid shark predation. Marine Ecology Progress Series 387:287293.

Wirsing, A. J., M. R. Heithaus, and L. M. Dill. 2006. Tiger shark (Galeocerdo cuvier) abundance and growth in a subtropical embayment: evidence from 7 years of standardized fishing effort. Marine Biology 149:961-968.

Wirsing, A. J., M. R. Heithaus, and L. M. Dill. 2007a. Can you dig it? Use of excavation, a risky foraging tactic, by dugongs is sensitive to predation danger. Animal Behaviour 74:10851091 .

Wirsing, A. J., M. R. Heithaus, and L. M. Dill. 2007b. Fear factor: do dugongs (Dugong dugon) trade food for safety from tiger sharks (Galeocerdo cuvier)? Oecologia 153:10311040.

Wirsing, A. J., M. R. Heithaus, and L. M. Dill. 2007c. Living on the edge: dugongs prefer to forage in microhabitats that allow escape from rather than avoidance of predators. Animal Behaviour 74:93-101. 
Wirsing, A. J., K. E. Cameron, and M. R. Heithaus. 2010. Spatial responses to predators vary with prey escape mode. Animal Behaviour 79:531-537.

Wu, L., et al. 2012. Enhanced warming over the global subtropical western boundary currents. Nature Climate Change 2:161-166.
Zarnetske, P. L., D. K. Skelly, and M. C. Urban. 2012. Biotic multipliers of climate change. Science 336:1516-1518.

Zuur, A. F., E. N. Ieno, N. J. Walker, A. A. Saveliev, and G. M. Smith. 2009. Mixed effects models in ecology with R. Springer, Berlin, Germany.

\section{SUPPORTING INFORMATION}

Additional supporting information may be found online at: http://onlinelibrary.wiley.com/doi/10.1002/ecm.1365/full

\section{Data Availability}

Data are available from the Dryad Digital Repository: https://doi.org/10.5061/dryad.7sg523n 